\title{
On the role of electric vehicles towards low-carbon energy systems: Italy and Germany in comparison
}

\author{
Sara Bellocchia, Kai Klöckner ${ }^{c}$, Michele Manno ${ }^{a *}$, Michel Noussan ${ }^{b}$, Michela Vellini $^{a}$ \\ aDepartment of Industrial Engineering, University of Rome Tor Vergata, Rome, Italy \\ e-mail: sara.bellocchi@uniroma2.it, michele.manno@uniroma2.it, vellini@ing.uniroma2.it \\ bFondazione Eni Enrico Mattei, Milan, Italy \\ e-mail: michel.noussan@feem.it \\ 'School of Business and Economics Chair of Management Accounting, RWTH Aachen University, \\ Aachen, Germany \\ e-mail: kloeckner@controlling.rwth-aachen.de
}

${ }^{*}$ Corresponding author: Via del Politecnico 100133 Roma, +390672597215

\begin{abstract}
Electric vehicles can play a major role in the transition towards low-carbon energy systems, but the related increase in electricity demand inevitably affects the strategic planning of the overall energy system as well as the definition of the optimal power generation mix. With this respect, the impact of electric vehicles may vary significantly depending on the composition of both total primary energy supply and electricity generation sector. In this study Italy and Germany are compared to highlight how a similarity in their renewable shares not necessarily leads to similar results in $\mathrm{CO}_{2}$ emissions reduction. Different energy scenarios are simulated with the help of EnergyPLAN software assuming a progressive increase in renewable energy sources capacity and electric vehicles penetration. Results show that, for the German case, the additional electricity required leads to a reduction in $\mathrm{CO}_{2}$ emissions only if renewable capacity increases significantly, whereas the Italian energy system benefits from transport electrification even at low renewable capacity. With a sixfold increase in renewables capacity and assuming a complete electrification of private transportation where EV charging strategy is regulated to enhance renewable integration, $\mathrm{CO}_{2}$ emissions can be reduced by $22 \%$ and $39 \%$ for Italy and Germany respectively. However, this comes along with a remarkable renewable surplus, respectively equal to $15 \%$ and $28 \%$ of the total national production unless large-scale energy storage systems are deployed.
\end{abstract}

\section{KEYWORDS}

RES integration; electric vehicles; smart charging; EnergyPLAN; cross-country comparison; $\mathrm{CO}_{2}$ emissions reduction.

\section{NOMENCLATURE}

The following abbreviations have been used in the manuscript:

$\begin{array}{ll}\text { RES } & \text { Renewable Energy Sources } \\ \text { iRES } & \text { Intermittent Renewable Energy Sources } \\ \text { iRES2016 } & \text { Scenarios in which iRES installed capacity is equal to } 2016 \text { level } \\ 6 \text { xiRES } & \text { Scenarios in which iRES installed capacity is increased sixfold } 2016 \text { level } \\ \text { EV } & \text { Electric Vehicles } \\ \text { BEV } & \text { Battery Electric Vehicles } \\ \text { PHEV } & \text { Plug-in Hybrid Electric Vehicles } \\ \text { RES surplus } & \text { Potential excess of electricity generation from renewable sources, evaluated with } \\ & \text { respect to the total national electricity generation } \\ \text { RES share } & \text { Electricity generation from RES, evaluated with respect to the total national } \\ \text { iRES capacity growth factor } & \text { electricity generation } \\ \text { TPES } & \text { The ratio between iRES capacity in a given scenario and iRES2016 } \\ & \text { Total Primary Energy Supply }\end{array}$




\section{$\mathrm{PP}$}

$\mathrm{CHP}$
Power Plants (conventional back-up power stations)

Combined Heat and Power (cogeneration power plants)

\section{INTRODUCTION}

In response to the Paris Agreement on climate change [1] energy strategies in different countries have put their focus on electricity generation [2] and transportation [3], that at present rely on fossil fuels respectively for $73 \%$ [4] and $96 \%$ [5] of their total energy consumption at a global scale. In this context, national policies agree upon the strategic role of renewable energy sources (RES) and electric vehicles (EV) in curbing $\mathrm{CO}_{2}$ emissions [6]. Indeed, both RES capacity and EV sales are forecasted to grow significantly in the coming years [7].

Transport sector electrification is expected to play a key role in the progressive decarbonisation of energy systems in several ways. First, electrical motors can function as substitutes of fossil-fuelled engines to avoid tailpipe emissions. Second, the coupling of transport and electricity sectors allows excess electricity from RES to be utilised to charge electric vehicles. In this regard, previous studies have mainly focused on the general sense of purpose of RES integration and relating EV diffusion and quantified the reduction in $\mathrm{CO}_{2}$ emissions and RES surplus both at a national [6] or local scale [7], deduced techno-economic optimal future scenarios with different shares of EV and RES penetration [8] and designed mechanisms for the incentivisation of those [9].

Further, the aggregated battery capacity of $\mathrm{EV}$ is not only expected to provide negative balancing power in times of excess electricity, but also to provide positive balancing power in periods of high electricity demand and relatively low production through vehicle-to-grid strategies (V2G) [10]. Generally speaking, EV can worse or lessen peak load depending on the charging strategy [11]; having regard to drivers' behaviour and given sufficient quality and quantity of data exchange between the infrastructural components of EV charging infrastructure and electricity network operation, grid operators can charge and discharge batteries of parked EV according to system requirements. However, the uncertain nature of RES combined with the variability of driving patterns of EV require the charging process to be scheduled through a direct control approach and an optimisation problem needs to be solved when RES integration is to be maximised [12]. The better the EV charging processes are harmonized with systemic requirements through an intelligent scheduling, the less necessary is conventional electricity generation, the less electricity from RES needs to be curtailed or stored, less renewable power capacity is required and high renewable utilization targets can be met [13].

Although the mix of energy generation technologies obviously affects the benefits of EV penetration [14], energy system configuration, concerning the levels of RES integration and EV diffusion is mostly derived as an outcome variable. However, the benefits of electrification strongly depend on prior choices concerning the generation technology mix that underlies particular energy systems. In this context, this study aims to advance knowledge on the interaction between RES integration and transport sector electrification through the comparison of alternative energy system configurations and applies a bottomup simulation approach that allows to assess the consequences of upfront modelled Smart Energy System design alternatives that, based on a holistic approach, favour possible synergies among sectors.

Positive interactions between a high penetration of PV and EV, using a smart strategy to foster the deployment of EV day charging to conveniently exploit the surplus of PV generation, have been demonstrated for the Portuguese energy system: at a given PV penetration, as EV share grows, $\mathrm{CO}_{2}$ emission, along with excess of PV generation, is progressively reduced confirming the ability of EV to assist intermittent RES integration leading to an almost decarbonised energy system [15]. The impact of EV on the Croatian energy system analysed in [16] showed that the electrification of $50 \%$ of road transport could potentially reduce fuel consumption by $12.3 \%$ and $\mathrm{CO}_{2}$ emissions by $14.6 \%$ as compared to 2011 level. Synergies between RES and EV for the Croatian energy system are also confirmed in [17]. Prina et al. [8] developed an optimization tool coupled with EnergyPLAN tool to select the best techno-economic transition pathway between 2015 baseline and a possible 2050 scenario, acting only on the electricity sector. Lund and Kempton [18] analysed the role of EV in integrating RES into the Danish energy system including also the effect of the charging strategy adopted providing a comparison between night charging and smart charging. The impact of EV, that are assumed to fully replace the conventional vehicle fleet, is evaluated for a range of wind power growing from 0 to approximately $100 \%$ of the electricity demand.

For the present study, the energy sytems of Italy and Germany were both chosen as starting point for further modelling because, on the one hand, they present features that are shared by several other 
developed European countries with high renewable potential and large oil products consumption in the transportation sector, while, on the other hand, they significantly vary with regard to electricity supply mix. Specifically, Italy differs from Germany, and Nordic countries in general, in the availability of wind and solar energy, with this latter taking the lion's share among intermittent RES, as well as in the reliance on natural gas, rather than coal, for conventional electricity generation. Such differences become particularly important when electricity generation from RES is not available or not enough, depending on the installed capacity or the time of the year, and the additional electricity demand has to be provided by conventional power plants, thus limiting or nullifying the environmental benefits of EV especially when such plants are powered by carbon-intensive fuels [14] and making $\mathrm{CO}_{2}$ savings potential greater where renewable contribution to the electricity mix is higher [19].

In this framework, the present work aims at extending the available literature focusing on key measures towards the achievement of sustainable and decarbonised energy systems with a particular attention to the decarbonisation of private transport sector. Starting from a base-case scenario for Italy and Germany in 2016, possible future projections with progressively increasing shares of RES and EV have been defined, analysed and compared with the help of EnergyPLAN software in order to evaluate the energy system response to an ever-growing renewable installed capacity and electrification of transport sector. Broadening the existing literature, this study provides detailed insights on how the characterisation of particular energy systems, in terms of different electricity generation mix, affects the effectiveness of EV to function as an electricity storage system under different charging strategies. This study deals with the issues related to modelling and forecasting future energy scenarios including also the environmental and economic impact of the rise of technologies (RES and EV) that are regarded as a key measure towards the decarbonisation of a particular energy system. Results are discussed in terms of crucial environmental and economic indicators such as $\mathrm{CO}_{2}$ emissions, RES penetration, curtailments and system costs considering current political topics such as the nuclear and coal phase-out, ultimately providing possible recommendations and a variety of technical solutions that policy makers can rely on to define the optimal path towards a sustainable and effective national energy strategy.

\section{METHODS}

This section describes the main logic of EnergyPLAN tool and lists input values for the definition of a base case and future scenarios for Italy and Germany, along with the related sources that have been used.

EnergyPLAN is an energy modelling tool that performs energy balances of a given energy system by simulating its operation throughout the year on an hourly basis [20].

To perform an energy balance for a given country, a variety of input parameters are required. From demand side, they are represented by annual electricity, heating and cooling demand along with their hourly power distributions as well as yearly direct fuel consumption for transport, industry, residential and commercial sectors.

From supply side, power plants capacities, efficiencies and fuel shares for power generation must be provided, as well as hourly distributions of RES generation. Conventional power plants are classified as CHP (Combined Heat and Power) and PP (Power Plants) units. Heat supply is modelled through boilers for individual heating and CHP units for district heating and industrial processes.

Hourly distributions, which are required, as mentioned above, for energy demands and non-dispatchable RES generation supply, must be expressed as the ratio between the hourly-averaged power required at a particular hour and the yearly maximum value.

Details on all these input data are given in the following paragraphs.

\subsection{Base case scenario definition}

A base case scenario has been defined for both countries, represented respectively by the Italian and German energy systems in 2016, modelled in terms of their energy supply and demand with reference to the most updated data from reliable sources (electric grid operators, International Energy Agency and EU-funded research projects). Input data for base case scenarios, resulting from the analysis presented in the followings, are available at an online open access repository [21]. 


\subsubsection{Demand}

From demand side, the Italian and German energy system have been described in terms of electricity, heating and cooling loads as well as direct fuel consumption for transport and industry sectors.

\subsubsection{Electricity}

Table 1 shows gross electricity loads for both countries in 2016, along with the sources where these data were taken from. The software allows electricity for heating, cooling and transportation to be set directly by the user: as a result, the remaining non-mentioned electrical loads are implicitly contained in the overall electricity demand (which also includes energy for auxiliary systems and losses). Annual net import/export electricity has been also inserted as an input parameter.

An hourly distribution must be associated with yearly electricity load and net import/export to ultimately let the software work out power plants generation on an hourly basis, thus performing the energy balance between electricity demand and supply throughout the year.

Hourly power distributions used to characterise electricity demand and import/export are shown in Figures A.1 and A.2 in the Appendix of this paper for the Italian and German case respectively.

Table 1. Electricity loads in 2016

\begin{tabular}{lrrrr}
\hline & Consumption (TWh/year) & \multicolumn{2}{c}{ Source } \\
\hline & \multicolumn{1}{c}{ Italy } & Germany & Italy & Germany \\
\hline $\begin{array}{l}\text { Total national electricity } \\
\text { demand } \\
\text { of which: }\end{array}$ & $\mathbf{3 2 6 . 8 0}$ & $\mathbf{5 9 8 . 5 9}$ & {$[22]$} & {$[23]$} \\
Electricity for cooling & & & & \\
Electricity for heating (electric & 6.42 & 0.96 & {$[24-26]$} & {$[25,27]$} \\
boilers) & 8.37 & 43.04 & {$[28]$} & {$[27]$} \\
Electricity for heating (heat pumps) & 18.63 & 5.82 & {$[29]$} & {$[30,31]$} \\
Electricity for transport & 11.16 & 11.73 & {$[24]$} & {$[32]$} \\
\hline Import & 43.18 & 28.34 & {$[22]$} & {$[23]$} \\
Export & -6.15 & -78.86 & {$[22]$} & {$[23]$} \\
Net Import/Export & $\mathbf{3 7 . 0 3}$ & $-\mathbf{5 0 . 5 2}$ & & \\
\hline
\end{tabular}

\subsubsection{Heating and cooling}

Fuel consumption for space heating and sanitary hot water for residential and commercial sectors is shown in Table 2 along with the average boiler efficiency; such parameters define what EnergyPLAN refers to as "individual heating".

Table 2. Fuel consumption and efficiencies for individual heating in 2016

\begin{tabular}{lrrrr}
\hline & \multicolumn{2}{c}{ Consumption (TWh/year) } & \multicolumn{2}{c}{ Efficiency } \\
\hline & \multicolumn{1}{c}{ Italy } & $\begin{array}{c}\text { Germany } \\
\text { (Source:[24,26]) }\end{array}$ & $\begin{array}{c}\text { Italy } \\
\text { (Source:[32]) }\end{array}$ & $\begin{array}{c}\text { Germany } \\
\text { (Source:[33]) }\end{array}$ \\
(Source[33]) \\
\hline Coal boiler & - & 6.36 & - & - \\
Oil boiler & 29.19 & 214.61 & 0.90 & 0.90 \\
Natural gas boiler & 262.73 & 377.10 & 0.92 & 0.92 \\
Solar thermal & 1.73 & 8.74 & 0.90 & 0.90 \\
Biomass boiler & 79.44 & 95.04 & 0.85 & 0.85 \\
\hline
\end{tabular}

With particular reference to the Italian case, a study carried out by "Gestore dei Servizi Energetici" (GSE), the company identified by the State to pursue and achieve environmental sustainability, provides a breakdown of residential and services overall energy consumption among end uses (as in space heating, space cooling, sanitary hot water, cooking etc.) and energy sources in 2015 [26]. From such 
subdivision, the consumption allocated specifically to space heating has been derived as a percentage of the total for each of the energy sources involved and the values have been rescaled to 2016.

As concerns the German case, in the absence of a detailed breakdown among end uses for residential and commercial sectors, the overall energy consumption has been entirely allocated to individual heating with the exception of electricity consumption, whose usage for heating and cooling purposes has been estimated from two external sources: the German energy models available at Heat Roadmap Europe database, a EU-funded project for the development of a low carbon and cooling strategy for 14 EU countries [27] and from the latest report concerning the development of Renewable Energy Sources in Germany provided by Federal Ministry for Economic Affairs and Energy [30].

The overall thermal demand for individual heating can thus be evaluated, and it is equal to 394.23 and 643.46 TWh for Italy and Germany respectively. Heat pumps and electric boilers, whose electricity consumption has been previously set in Table 1, provide together for a thermal demand of $57.37 \mathrm{TWh}$ for the Italian case and 60.29 TWh for the German case. The value used for Seasonal Performance Factor (SPF, indicating the seasonally-averaged COP over the heating season) is based on actual measurement and reliable available data for both countries, resulting in 2.63 and 2.95 for Italy [29] and Germany $[30,31]$ respectively.

Once the annual fuel consumption is provided, annual $\mathrm{CO}_{2}$ emissions related to individual heating can also be derived using fuel emission factors as reported in the following of this section.

As shown in Table 1, electricity consumption for cooling is respectively equal to 0.96 and $6.42 \mathrm{TWh}$ for Germany and Italy; assuming a Seasonal Energy Efficiency Ratio (SEER, a commonly used measure of the average efficiency of cooling equipment that takes into account changes in operating conditions throughout the cooling season) of 5.5 for both countries [25] space cooling demand is equal to 5.27 and 35.33 TWh for the German and the Italian case.

Hourly distributions of individual heating and cooling demand are also required and used by the software to simulate on an hourly basis electricity generation needed to fulfil demand for heat pumps and electric boilers. Individual heating demand distribution takes also into account demand for sanitary hot water. Such distributions are shown in Figures A.3 and A.4 in the Appendix of this paper for Italy and Germany respectively.

With respect to Italy, heating distribution has been derived considering the overall national gas consumption considering that almost $70 \%$ of individual heating demand is fulfilled through natural gas. Its hourly distribution is provided by SNAM, the national society for natural gas transportation and storage, for the year 2016 [34]. Gas consumption for heating purposes only has been determined by subtracting industry, power plants and transportation usage.

As concerns the German case, heating and cooling distributions have been taken from Heat Roadmap Europe database [27]. Since the latest available models refer to the year 2015, it has been assumed that heating and cooling demand distributions stay the same in 2016.

District heating and heat demand for industrial processes have been also included, and values are listed in Table 3 for both countries.

Table 3. District heating and heat demand (TWh/year) at 2016

\begin{tabular}{lcr}
\hline & \multicolumn{1}{c}{ Italy } & \multicolumn{1}{c}{ Germany } \\
& (Source: [24]) & (Source:[32]) \\
\hline Energy industry own use & 16.24 & 3.48 \\
Residential and services & 13.86 & 64.06 \\
Industry & 31.82 & 49.69 \\
Total & $\mathbf{6 1 . 9 2}$ & $\mathbf{1 1 7 . 2 3}$ \\
\hline
\end{tabular}

CHP and DH plants cater for such demand, as described in detail in the following (see section 2.1.2).

\subsubsection{Industry and other fuel consumption}

Fuel consumption in the industry and other sectors (agriculture, fishing, forestry, energy industry own use and various non-specified areas) have been included as well to account for $\mathrm{CO}_{2}$ emissions also in these areas of the energy system. Data are shown in Table 4. 
Besides fuel consumption, EnergyPLAN allows to insert fuel losses estimated as a percentage of the total fuel consumed at the end of the analysis. Such losses have been set to $1.04 \%$ and $0.07 \%$ for coal and oil in Germany [32] and equal to $0.5 \%$ for natural gas in the Italian case [24].

Table 4. Industry and other sector fuel consumption (TWh/year) at 2016

\begin{tabular}{lrrrr}
\hline & \multicolumn{2}{c}{ Industry } & \multicolumn{2}{c}{ Other } \\
\hline & \multicolumn{1}{c}{ Italy } & Germany & \multicolumn{1}{c}{ Italy } & \multicolumn{1}{c}{ Germany } \\
(Source:[24]]) & (Source: [32]) & (Source:[24] & \multicolumn{1}{c}{ (Source: [32]) } \\
\hline Coal & 11.16 & 70.41 & 0.05 & 9.55 \\
Oil & 30.94 & 27.35 & 61.08 & 66.65 \\
Natural gas & 97.23 & 226.62 & 27.35 & 14.62 \\
Biomass and waste & 7.64 & 45.43 & 73.22 & 6.22 \\
\hline
\end{tabular}

\subsubsection{Transport}

With respect to the transport sector, energy demand has been modelled by including fuel and electricity consumption as listed in Table 5 for both countries. In the Italian case, fuel consumption projection for 2016 provided by "Istituto Superiore Per la Ricerca Ambientale" (ISPRA) [35] has been considered to derive how the overall consumption is distributed among fuels, and adjusted according to total energy consumption in the transport sector as provided by IEA for the same year [24]. As for Germany, transport-related energy consumption has been derived from data published by AGEB for the year 2016 [36].

Table 5. Transport sector fuel and electricity consumption (TWh/year) at 2016

\begin{tabular}{lrr}
\hline & \multicolumn{1}{c}{ Italy } & \multicolumn{1}{c}{ Germany } \\
& (Source: [24,35]) & (Source: [36]) \\
\hline JP (Jet Fuel) & 8.05 & 108.06 \\
Diesel & 262.63 & 423.94 \\
$\quad$ of which biodiesel & 11.72 & 29.94 \\
Petrol & 88.42 & 197.11 \\
$\quad$ of which biopetrol & 0.29 & 0 \\
Natural gas & 12.86 & 1.62 \\
LPG & 21.24 & 4.67 \\
Electricity & 11.16 & 11.74 \\
\hline
\end{tabular}

Given the negligible share of EV in 2016, electricity consumption can be allocated to other means of transportation such as trains and electric trams. Moreover, since electricity demand for transportation is ultimately fulfilled by power plants, its distribution has to be included in the model. Figure A.5, reported in the Appendix of this paper, shows the distribution of transportation demand [27], the same for both countries; only seven days have been displayed to highlight the daily pattern over a week. It is worth recalling that this is battery demand, not electric system demand, as the vehicles are necessarily disconnected from the grid while driving. Thus, such distribution can be interpreted as the hourly battery discharging for 1 week and it is used by EnergyPLAN to work out, on an hourly basis, how many cars are driving and consequently not connected to the grid. The fraction of the EV fleet that is available to interact with the electrical system at any given hour can be estimated from the maximum share of cars that are driving during peak demand hour ( $\left.\mathrm{V} 2 \mathrm{G}_{\text {Drivingshare }}\right)$ and from the percentage of those parked cars

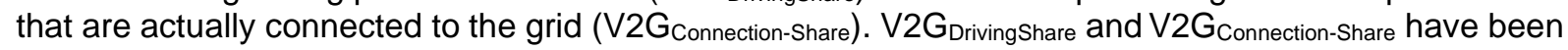
respectively set to 0.2 and 0.7 according to [18].

\subsubsection{Supply}

Energy supply has been modelled including the current technology mix deployed to satisfy power and thermal loads and ultimately achieve an hourly energy balance throughout the year. 


\subsubsection{Heat and electricity: conventional power plants}

While individual heating demand has been already discussed in section 2.1.1.2, CHP and DH plants have been modelled to cater for district heating requirements for both countries. Among CHP plants, EnergyPLAN allows to select large CHP plants able to operate, if required, in electricity mode only. Such capacity is thus included in conventional power plants overall capacity (PP). Capacities and efficiencies are shown in Table 6.

Power plants fuel consumption has to be also considered to properly assess the overall $\mathrm{CO}_{2}$ emissions related to electricity generation. With this regard, the software allows to set how the overall power plant energy consumption is distributed among fuels. Table 7 shows data used for Italy and Germany.

Table 6. Conventional power and cogeneration plants: installed capacity and efficiency at 2016

\begin{tabular}{lrrrrrr}
\hline & \multicolumn{2}{c}{ Italy } & \multicolumn{4}{c}{$\begin{array}{c}\text { Germany } \\
\text { (Source:[32,38]) }\end{array}$} \\
\hline & Capacity $(\mathrm{GW})$ & $\eta_{\mathrm{el}}$ & \multicolumn{1}{c}{$\eta_{\text {th }}$} & Capacity $(\mathrm{GW})$ & $\eta_{\mathrm{el}}$ & $\eta_{\text {th }}$ \\
\hline $\mathrm{PP}$ & 58.95 & 0.43 & - & 86.82 & 0.40 & - \\
$\mathrm{CHP}$ & 26.25 & 0.39 & 0.22 & 51.16 & 0.39 & 0.30 \\
\hline
\end{tabular}

Table 7. Conventional power and cogeneration plants: fuel distribution (TWh/year) at 2016

\begin{tabular}{lrrrr}
\hline & \multicolumn{2}{c}{ CHP } & \multicolumn{2}{c}{ PP } \\
\hline & \multicolumn{1}{c}{ Italy } & Germany & \multicolumn{1}{c}{ Italy } & Germany \\
& (Source:[24]) & (Source:[32]) & (Source:[24,37]) & (Source:[32]) \\
\hline Coal & 9.59 & 75.52 & 100.58 & 702.76 \\
Oil & 44.36 & 5.07 & 36.54 & 12.57 \\
Natural gas & 179.75 & 140.69 & 219.60 & 125.22 \\
Biomass & 39.02 & 98.07 & 62.50 & 66.27 \\
\hline
\end{tabular}

District heating boilers are modelled to produce 35.83 TWh [32] and 1.14 TWh [24] of thermal energy for Germany and Italy respectively (with an overall efficiency equal to 0.77 and 0.71 ).

Finally, nuclear power plants have been included in the German energy scenario: the overall capacity has been set to $10.8 \mathrm{GW}$ [38], with an electric efficiency of 0.33 [32].

\subsubsection{Renewable electricity generation}

Besides conventional power plants, electricity provided by renewable energy sources has to be modelled to completely define the technology mix to cater for national electricity demand. Their installed capacities are listed in Table 8.

RES hourly distribution is shown in Figures A.6 and A.7, in the Appendix section, for the Italian and German case respectively along with the related sources $([39,40])$.

Table 8. Renewable energy installed capacity (GW) at 2016

\begin{tabular}{lrr}
\hline Technology & \multicolumn{1}{c}{ Italy } & \multicolumn{1}{c}{ Germany } \\
(Source: [37]) & (Source: [38]) \\
\hline Onshore wind & 9.41 & 45.28 \\
Offshore wind & - & 4.15 \\
Photovoltaic & 19.28 & 40.68 \\
River Hydro & 5.43 & 3.95 \\
Dammed Hydro & 18.72 & 1.54 \\
Geothermal & 0.82 & 0.04 \\
\hline
\end{tabular}




\subsubsection{Model validation}

Base case scenarios have been validated comparing critical indicators against actual data at 2016 as displayed in Table 9. Variation with respect to actual data is within $2.3 \%$. Primary energy supply related to non-energy uses has been subtracted from the actual value as they are not included in the energy system model; RES electricity production does not include biomass, which is instead included in PP production and RES penetration is expressed as a percentage of total national electricity production.

Table 9. Model validation.

\begin{tabular}{|c|c|c|c|c|c|}
\hline Country & Indicator & Model & Actual & Source & Difference \\
\hline \multirow{5}{*}{ 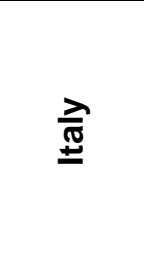 } & $\mathrm{CO}_{2}$ emissions $[\mathrm{Mt}]$ & 324.9 & 325.7 & {$[54]$} & $-0.24 \%$ \\
\hline & TPES [Mtoe] & 147.8 & 144.7 & {$[38,54]$} & $2.17 \%$ \\
\hline & RES electricity (excl. biomass) [TWh] & 90.3 & 90.3 & [50] & $-0.01 \%$ \\
\hline & PP electricity $[\mathrm{TWh}]$ & 93.7 & 93.6 & [50] & $0.15 \%$ \\
\hline & CHP electricity [TWh] & 105.9 & 105.1 & [50] & $0.69 \%$ \\
\hline \multirow{5}{*}{ 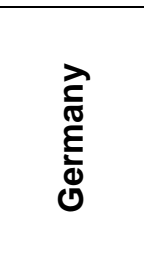 } & $\mathrm{CO}_{2}$ emissions $[\mathrm{Mt}]$ & 723.1 & 731.6 & [54] & $-1.16 \%$ \\
\hline & TPES [Mtoe] & 295.2 & 288.6 & {$[38,54]$} & $2.27 \%$ \\
\hline & RES electricity (excl. biomass) [TWh] & 137.5 & 137.4 & [55] & $0.12 \%$ \\
\hline & PP electricity $[\mathrm{TWh}]$ & 301.5 & 296.0 & [38] & $1.87 \%$ \\
\hline & CHP electricity [TWh] & 125.5 & 125.5 & [38] & $0.00 \%$ \\
\hline
\end{tabular}

\section{$2.2 \quad$ Future scenarios modelling}

Future scenarios have been modelled in EnergyPLAN assuming progressively growing shares of RES, taking into account potential limits for renewable sources, and EV, up to an entire replacement of conventional vehicle fleet.

\subsubsection{Electricity generation}

As concerns electricity generation, renewable installed capacities for intermittent sources (iRES), as in wind and solar, have been linearly increased for the German case up to the maximum value derived according to 2050 energy policy target which leads to an overall growth equal to approximately 6 times the corresponding 2016 total iRES installed capacity (6xiRES). With this respect, to provide an effective comparison among energy systems, the same sixfold increase in iRES capacity has been kept for the Italian case and divided among sources taking into account an upper limit for wind, conservatively set at $17.15 \mathrm{GW}$ according to National Wind Energy Association (ANEV) projections at 2030 [41]. Values are displayed for each source in Table 10.

Table 10 . iRES capacity values (GW)

\begin{tabular}{lrrrr}
\hline \multirow{2}{*}{ Technology } & \multicolumn{2}{c}{ Italy } & \multicolumn{2}{c}{ Germany } \\
\cline { 2 - 5 } & iRES2016 & \multicolumn{1}{c}{ 6xiRES } & \multicolumn{1}{c}{ iRES2016 } & 6xiRES \\
& (Source:[37]) & & (Source:[38]) & (Source:[42]) \\
\hline Onshore wind & 9.41 & 16.00 & 45.28 & 198.00 \\
Offshore wind & - & 1.15 & 4.15 & 54.00 \\
PV & 19.28 & 150.66 & 40.68 & 275.00 \\
\hline Total & $\mathbf{2 8 . 6 9}$ & $\mathbf{1 6 7 . 8 1}$ & $\mathbf{9 0 . 1 1}$ & $\mathbf{5 2 7 . 0 0}$ \\
\hline
\end{tabular}

Assumptions have been also made with respect to fossil fuel consumption for electricity production and conventional power plants. The option of coal phase-out has been implemented for both countries, leading to a reduction in power capacity of $8.20 \mathrm{GW}$ for the Italian case [43] and $42.48 \mathrm{GW}$ (28.89 GW for CHP and $13.59 \mathrm{GW}$ for PP) for Germany [38]. Additionally, a nuclear phase-out has been implemented for the German case, which translates in the decommissioning of $10.8 \mathrm{GW}$ of nuclear capacity. 
Finally, with respect to import/export management for the Italian case, RES surplus has been considered to be able to replace, at any given hours of each day of the year, electricity import when they both happen to occur simultaneously.

\subsubsection{Private transport}

Future scenarios for transportation sector have been derived assuming a linear decrease in petrol and diesel cars combined with a simultaneous progressive replacement by EV up to a complete substitution of the conventional vehicle fleet, keeping the total number of vehicles stable at 2016 level, a reasonable assumption according to future projection for the Italian case [43] and resulting, for the German case, from a combination of an increase in new mobility services, future urban development policies based on needs-oriented remodelling of the street environment [44], population and GDP growth rate.

The impact of private transport only within the whole transportation sector needs to been estimated in terms of fuel consumption; conventional and electric vehicles were divided into different categories according to their market segment (as in small, medium and large) based on vehicles registrations over the last ten years for the Italian case [45] and using recent data on German road vehicles fuel consumption disaggregated by segment [46].

Average fuel economy for conventional cars has been derived from manufacturers' data and adjusted in each category to meet the more realistic overall higher value reported in Unione Petrolifera technical report [43].

For the Italian case, the annual driving distance was set to 7280 and $13650 \mathrm{~km} /$ year respectively for petrol and diesel cars [43]. With respect to the German case, annual distance covered by petrol and diesel vehicles has been set to 10260 and $18525 \mathrm{~km} /$ year, derived as a projection to 2016 from historical data for Germany reported in [47].

EV technical specifications were evaluated as a weighted average of the actual circulating fleet composition for both countries considering new registrations from 2015 onwards [45,48] including also electricity consumption for auxiliary systems and real driving conditions based on the latest EV models available data [49]. Petrol consumption was also taken into account for hybrid plug-in electric vehicles (PHEV) when exceeding the full-electric range. PHEV are also assumed to represent $30 \%$ of the EV medium and large size vehicle segment in future scenarios thus leading to an overall BEV/PHEV relative share in the total EV fleet in line with future projections [50]. Final electricity consumption for EV and PHEV was calculated considering a $90 \%$ charging efficiency. EV are assumed to cover an average distance between petrol and diesel, i.e. 10367 and $13027 \mathrm{~km} / \mathrm{year}$ for Italy and Germany respectively. An example, referring to a $50 \%$ replacement of the conventional fleet, is shown in Tables 11-14.

Table 11. Conventional vehicles fuel consumption at $50 \%$ replacement - Italy

\begin{tabular}{|c|c|c|c|c|c|c|}
\hline & Size & Share & $\begin{array}{l}\text { Initial vehicles } \\
\qquad\left(\times 10^{6}\right)\end{array}$ & $\begin{array}{l}\text { Remaining } \\
\text { vehicles } \\
\left(\times 10^{6}\right) \\
\end{array}$ & $\begin{array}{l}\text { Consumption } \\
(\mathrm{l} / 100 \mathrm{~km})\end{array}$ & $\begin{array}{l}\text { Consumption } \\
\text { (TWh/year) }\end{array}$ \\
\hline \multirow{4}{*}{$\begin{array}{l}\overline{0} \\
\frac{1}{0} \\
0\end{array}$} & Small & 0.86 & 13.75 & 6.87 & 6.19 & 27.90 \\
\hline & Medium & 0.13 & 2.04 & 1.02 & 6.79 & 4.54 \\
\hline & Large & 0.01 & 0.12 & 0.06 & 9.38 & 0.37 \\
\hline & Total & & 15.91 & 7.95 & & 32.81 \\
\hline \multirow{4}{*}{$\begin{array}{l}\bar{\Phi} \\
\Phi \\
\overline{0}\end{array}$} & Small & 0.35 & 5.27 & 2.63 & 4.79 & 16.87 \\
\hline & Medium & 0.61 & 9.06 & 4.53 & 5.56 & 33.71 \\
\hline & Large & 0.04 & 0.64 & 0.32 & 8.09 & 3.44 \\
\hline & Total & & 14.96 & 7.48 & & 54.02 \\
\hline
\end{tabular}


Table 12. EV electricity and PHEV fuel consumption at $50 \%$ replacement - Italy

\begin{tabular}{lrrrrrr}
\hline Size & Share & $\begin{array}{r}\text { Consumption } \\
(\mathrm{kWh} / 100 \mathrm{~km})\end{array}$ & $\begin{array}{c}\text { Vehicles } \\
\left(\times 10^{6}\right)\end{array}$ & $\begin{array}{c}\text { Electricity } \\
\text { consumption } \\
(\mathrm{TWh} / \text { year })\end{array}$ & $\begin{array}{c}\text { Battery } \\
\text { storage } \\
(\mathrm{GWh})\end{array}$ & $\begin{array}{r}\text { PHEV fuel } \\
\begin{array}{c}\text { consumption } \\
(\mathrm{TWh} / \text { year })\end{array}\end{array}$ \\
\hline Small & 0.62 & 16.39 & 9.51 & 17.95 & 154.57 & - \\
Medium & 0.36 & 18.44 & 5.55 & 11.79 & 155.53 & 0.54 \\
Large & 0.02 & 22.11 & 0.38 & 0.96 & 26.01 & 0.08 \\
\hline Total & & & $\mathbf{1 5 . 4 3}$ & $\mathbf{3 0 . 7 0}$ & $\mathbf{3 3 6 . 1 1}$ & $\mathbf{0 . 6 2}$ \\
\hline
\end{tabular}

Table 13. Conventional vehicles fuel consumption at $50 \%$ replacement - Germany

\begin{tabular}{|c|c|c|c|c|c|c|}
\hline & Size & Share & $\begin{array}{l}\text { Initial vehicles } \\
\qquad\left(\times 10^{6}\right)\end{array}$ & $\begin{array}{l}\text { Remaining } \\
\text { vehicles } \\
\left(\times 10^{6}\right)\end{array}$ & $\begin{array}{l}\text { Consumption } \\
(\mathrm{l} / 100 \mathrm{~km})\end{array}$ & $\begin{array}{l}\text { Consumption } \\
\text { (TWh/year) }\end{array}$ \\
\hline \multirow{4}{*}{ 홍 } & Small & 0.32 & 9.59 & 4.80 & 6.19 & 27.44 \\
\hline & Medium & 0.58 & 17.39 & 8.69 & 6.79 & 54.53 \\
\hline & Large & 0.10 & 3.00 & 1.50 & 9.38 & 13.00 \\
\hline & Total & & 29.97 & 14.99 & & 94.97 \\
\hline \multirow{4}{*}{$\begin{array}{l}\bar{\Phi} \\
\Phi \\
.0 \\
\bar{D}\end{array}$} & Small & 0.09 & 1.36 & 0.68 & 4.79 & 5.90 \\
\hline & Medium & 0.70 & 10.49 & 5.24 & 5.56 & 52.97 \\
\hline & Large & 0.21 & 3.24 & 1.62 & 8.09 & 23.84 \\
\hline & Total & & 15.09 & 7.54 & & 82.71 \\
\hline
\end{tabular}

Table 14. EV electricity and PHEV fuel consumption at 50\% replacement - Germany

\begin{tabular}{lrrrrrr}
\hline Size & Share & $\begin{array}{r}\text { Consumption } \\
(\mathrm{kWh} / 100 \mathrm{~km})\end{array}$ & $\begin{array}{c}\text { Vehicles } \\
\left(\times 10^{6}\right)\end{array}$ & $\begin{array}{c}\text { Electricity } \\
\text { consumption } \\
(\text { TWh/year })\end{array}$ & $\begin{array}{c}\text { Battery } \\
\text { storage } \\
(\mathrm{GWh})\end{array}$ & $\begin{array}{c}\text { PHEV fuel } \\
\text { consumption } \\
\text { (TWh/year) }\end{array}$ \\
\hline Small & 0.24 & 16.72 & 5.47 & 13.25 & 90.13 & - \\
Medium & 0.62 & 18.40 & 13.94 & 37.11 & 368.62 & 3.99 \\
Large & 0.14 & 22.20 & 3.12 & 10.03 & 215.25 & 1.73 \\
\hline Total & & & $\mathbf{2 2 . 5 3}$ & $\mathbf{6 0 . 2 4}$ & $\mathbf{6 7 1 . 8 0}$ & $\mathbf{5 . 7 2}$ \\
\hline
\end{tabular}

With reference to charging strategy two different options have been taken into account:

- Dump charge: Vehicles are charged exclusively according to driver's needs/habits;

- Smart charge: EV charge during low-power demand in order to meet drivers' needs to recharge the vehicle at a certain time as well as to avoid grid overloading.

The graphs displayed in the Results and discussion section refer to the smart charge option.

\subsubsection{Cost structure}

As concerns costs, economic data are based on projections to 2050 from the EU-funded Heat Roadmap Europe project [27], Tables 15 and 16 display data relevant to the analysis, i.e. RES costs and fuel price.

Table 15. Intermittent RES related costs at 2050 (Source:[27])

\begin{tabular}{llccc}
\hline Country & Technology & $\begin{array}{c}\text { Investment } \\
\left(\mathrm{M} € / \mathrm{MW}_{\mathrm{e}}\right)\end{array}$ & $\begin{array}{c}\text { Period } \\
(\text { Years })\end{array}$ & $\begin{array}{c}\text { O. \& M. } \\
(\% \text { of Inv. }\end{array}$ \\
\hline Italy & Onshore wind & 0.86 & 30 & 3.41 \\
& Offshore wind & 1.39 & 30 & 1.93 \\
& Photovoltaic & 0.66 & 40 & 1.11 \\
\hline
\end{tabular}




\begin{tabular}{lllll}
\hline Germany & Onshore wind & 0.91 & 30 & 3.40 \\
& Offshore wind & 1.47 & 30 & 1.93 \\
& Photovoltaic & 0.70 & 40 & 1.11 \\
\hline
\end{tabular}

Table 16. Fuel price (€/GJ) (Source:[27])

\begin{tabular}{lr}
\hline Fuel & Price \\
\hline Coal & 2.4 \\
Fuel Oil & 9.7 \\
Diesel fuel & 12.1 \\
Petrol/JP & 12.1 \\
Natural gas & 9.3 \\
LPG & 13.4 \\
Biomass & 8.6 \\
\hline
\end{tabular}

A weighted average price for EV has been considered from the current vehicle fleet composition. Medium and large EV price has been evaluated considering such category made up of $30 \% \mathrm{BEV}$ and $70 \%$ PHEV. As concerns petrol and diesel cars, for both countries purchase costs have been derived from manufacturers' prices for the most common vehicles for each category, chosen as representative of the particular segment. Resulting data are summarized in Table 17.

Table 17. Conventional and EV purchase costs $(k €)$

\begin{tabular}{cllcc}
\hline Country & Category & Petrol & Diesel & EV \\
\hline Italy & Small & 12.39 & 13.45 & 29.81 \\
& Medium & 23.40 & 21.00 & 37.03 \\
& Large & 62.65 & 58.17 & 88.33 \\
\hline Germany & Small & 13.60 & 16.20 & 24.96 \\
& Medium & 23.40 & 26.40 & 36.43 \\
& Large & 62.65 & 60.43 & 87.68 \\
\hline
\end{tabular}

Given the foreseen decrease in battery costs in the medium-long term future [51,52] a parametric analysis has been also undertaken with respect to EV price, evaluating the effect of possible reasonable future price reductions for EV as compared to conventional vehicles. In particular, cost analysis has been carried out under three different EV purchasing cost assumptions:

- EV price @2016: EV price is stable at 2016 level;

- EV price reduced: average between current EV and conventional car price;

- $\quad E V=C o n v e n t i o n a l: ~ E V$ price equals that of conventional cars.

\section{RESULTS AND DISCUSSION}

The variety of scenarios defined according to the above-mentioned assumptions have been compared using environmental and techno-economic indicators as $\mathrm{CO}_{2}$ emissions variation, RES penetration and surplus. These latter have been evaluated with respect to the domestic electricity production.

\subsection{RES and EV positive interactions}

Figure 1 displays how the increase in iRES capacity with respect to 2016 (labelled as iRES capacity growth factor) affects two crucial energy indicators, namely $\mathrm{CO}_{2}$ emissions and RES surplus, for the Italian and German case respectively; EV are assumed to be charged under a smart strategy. 

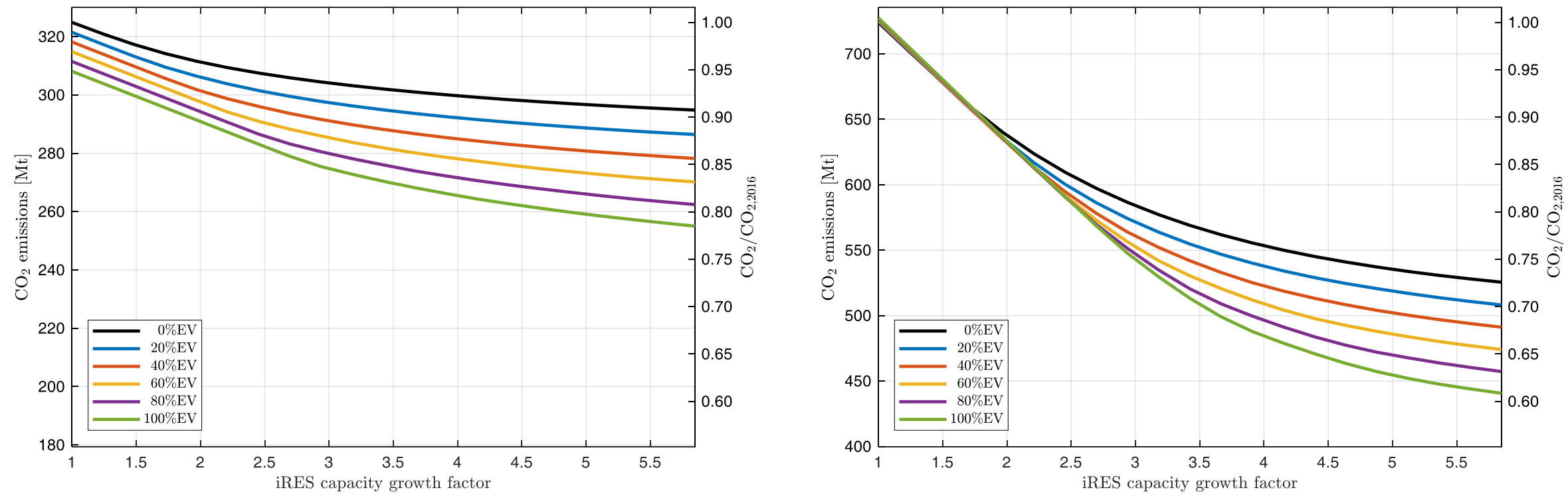

Figure 1. $\mathrm{CO}_{2}$ emissions at increasing iRES capacity - Italy (left) and Germany (right) 
While the Italian energy system always benefits from EV, in Germany the additional electricity required for EV charging leads to a different trend in $\mathrm{CO}_{2}$ emissions, so that, when iRES capacity is below a certain threshold, emissions remain almost unchanged irrespective of EV penetration (and actually slightly increase). Moreover, as discussed in Section 3.3, for the German case the overall installed capacity for electricity generation is not adequate to fulfil the increase in electricity demand that arises under significant EV penetrations, thus requiring additional electricity to be imported from neighbouring countries (or, possibly, additional increase of existing installing capacity). For such scenarios, $\mathrm{CO}_{2}$ emissions equivalent to additional import have been calculated as if they were produced by national PP capacity, that is, German PP specific $\mathrm{CO}_{2}$ emissions have been applied to the additional import.

On the other hand, at higher levels of RES penetration (approximately twice the base case capacity), the interaction between RES and EV proves to be beneficial for both countries, even more effective in the German case where RES replace a more carbon-intensive electricity generation sector. In particular, without including the electrification of transport sector, if RES are increased up to 6 times the overall 2016 capacity, $\mathrm{CO}_{2}$ emissions can be reduced by $9 \%$ and $27 \%$ for Italy and Germany respectively. At the highest RES level, EV allow a further reduction of $\mathrm{CO}_{2}$ emissions down to $22 \%$ and $39 \%$ for Italy and Germany respectively by absorbing the otherwise-curtailed renewable surplus, which is reduced from $29 \%$ to $15 \%$ of total electricity production for Italy and from $50 \%$ to $28 \%$ for Germany (Tables 18 and 19).

Nonetheless, it is worth mentioning that curtailments cannot be effectively reduced unless the deployment of renewable sources is extended, besides transportations, also to other sectors of the energy system to maximise the positive effects of sector coupling [53], or suitable grid-scale electricity storage systems become available and widely used [54].

\subsection{Impact of charging strategy}

Tables 18 and 19 and show $\mathrm{CO}_{2}$ variations (with respect to 2016 base-case), RES penetration and surplus (both expressed as a percentage of the total production) for increasing EV penetrations comparing dump and smart charging strategies at the highest RES level.

For both countries, shifting from dump to smart strategy results in a positive effect on $\mathrm{CO}_{2}$ emissions; when a smart charge is implemented Italy features a higher percentage variation than Germany with respect to results obtained using a dump charge. This is due to the particular uneven distribution of the Italian RES potential generation throughout the day; conversely, the charging strategy shows a lower effect for the German case where potential RES surplus, more uniformly distributed, lessens the negative impact of dump charge. In fact, vehicle charged at evening/night time can still exploit some RES power related to wind electricity generation, as opposed to Italy where renewable production occurs mostly during the day due to the higher solar power share. As a result, in terms of percentage change, RES penetration variation, and subsequent RES surplus, is higher for the Italian case when a smart charge is applied as a relatively higher share of renewable power can be incorporated in the energy system.

Table 18. $\mathrm{CO}_{2}$ variations, RES penetration and surplus at $6 \times$ iRES - Italy

\begin{tabular}{|c|c|c|c|c|c|c|}
\hline & $0 \% E V$ & $20 \% E V$ & $40 \% E V$ & $60 \% \mathrm{EV}$ & $80 \% E V$ & $100 \% E V$ \\
\hline \multicolumn{7}{|l|}{$\mathrm{CO}_{2}[\%]$} \\
\hline Dump & $-9.2 \%$ & $-10.9 \%$ & $-12.7 \%$ & $-13.6 \%$ & $-15.0 \%$ & $-16.3 \%$ \\
\hline Smart & $-9.2 \%$ & $-11.8 \%$ & $-14.3 \%$ & $-16.8 \%$ & $-19.2 \%$ & $-21.5 \%$ \\
\hline Variation & $0.0 \%$ & $7.9 \%$ & $13.1 \%$ & $23.3 \%$ & $28.3 \%$ & $31.5 \%$ \\
\hline \multicolumn{7}{|c|}{ RES penetration [\% of tot. prod.] } \\
\hline Dump & $51.2 \%$ & $53.1 \%$ & $52.3 \%$ & $50.1 \%$ & $48.7 \%$ & $47.3 \%$ \\
\hline Smart & $51.2 \%$ & $52.4 \%$ & $53.5 \%$ & $54.3 \%$ & $55.0 \%$ & $55.3 \%$ \\
\hline Variation & $0.0 \%$ & $-1.4 \%$ & $2.2 \%$ & $8.4 \%$ & $12.9 \%$ & $16.9 \%$ \\
\hline \multicolumn{7}{|c|}{ RES surplus [\% of tot. prod.] } \\
\hline Dump & $29.3 \%$ & $28.1 \%$ & $26.3 \%$ & $25.9 \%$ & $25.0 \%$ & $24.2 \%$ \\
\hline Smart & $29.3 \%$ & $26.1 \%$ & $23.0 \%$ & $20.1 \%$ & $17.4 \%$ & $15.0 \%$ \\
\hline Variation & $0.0 \%$ & $-7.1 \%$ & $-12.5 \%$ & $-22.4 \%$ & $-30.4 \%$ & $-38.1 \%$ \\
\hline
\end{tabular}


Table 19. $\mathrm{CO}_{2}$ variations, RES penetration and surplus at $6 \times$ iRES - Germany

\begin{tabular}{|c|c|c|c|c|c|c|}
\hline & $0 \% \mathrm{EV}$ & $20 \% E V$ & $40 \% \mathrm{EV}$ & $60 \% E V$ & $80 \% E V$ & $100 \% \mathrm{EV}$ \\
\hline \multicolumn{7}{|l|}{$\mathrm{CO}_{2}[\%]$} \\
\hline Dump & $-27.4 \%$ & $-27.3 \%$ & $-28.5 \%$ & $-29.4 \%$ & $-30.2 \%$ & $-31.0 \%$ \\
\hline Smart & $-27.4 \%$ & $-29.8 \%$ & $-32.2 \%$ & $-34.5 \%$ & $-36.8 \%$ & $-39.1 \%$ \\
\hline Variation & $0.0 \%$ & $9.4 \%$ & $13.0 \%$ & $17.4 \%$ & $21.9 \%$ & $26.3 \%$ \\
\hline \multicolumn{7}{|c|}{ RES penetration [\% of tot. prod.] } \\
\hline Dump & $60.6 \%$ & $60.3 \%$ & $60.0 \%$ & $59.4 \%$ & $58.5 \%$ & $57.7 \%$ \\
\hline Smart & $60.6 \%$ & $61.8 \%$ & $62.9 \%$ & $64.0 \%$ & $64.9 \%$ & $65.8 \%$ \\
\hline Variation & $0.0 \%$ & $2.5 \%$ & $4.9 \%$ & $7.8 \%$ & $10.9 \%$ & $14.0 \%$ \\
\hline \multicolumn{7}{|c|}{ RES surplus [\% of tot. prod.] } \\
\hline Dump & $50.4 \%$ & $50.6 \%$ & $47.0 \%$ & $43.9 \%$ & $41.2 \%$ & $39.0 \%$ \\
\hline Smart & $50.4 \%$ & $45.2 \%$ & $40.5 \%$ & $36.0 \%$ & $31.8 \%$ & $28.0 \%$ \\
\hline Variation & $0.0 \%$ & $-10.7 \%$ & $-13.8 \%$ & $-18.0 \%$ & $-22.8 \%$ & $-28.2 \%$ \\
\hline
\end{tabular}

This phenomenon is visible in Figures 2 and 3, which show boxplots related to electricity demand normalized distributions throughout the 24 hours for the whole year considering dump and smart charge at $6 \times \mathrm{iRES}$ and EV entirely replacing the conventional vehicle fleet $(100 \% \mathrm{EV})$. Electricity demand distribution is reshaped from dump to smart strategy according to the availability of RES surplus, shifting night-hour load to day hours characterised by an abundance of renewable power. The contribution of conventional power plants and RES surplus can thus be partly reduced as shown in Figures 4-7, representing, for the Italian and the German case respectively, hourly demand and supply by RES and conventional sources for approximately ten days of February, in which it can be also observed how the higher share of wind generation may reduce issues related to an unregulated EV charge.

The variation of $\mathrm{CO}_{2}$ emissions divided by energy sectors is displayed in Figures 8-13 for base-case and for iRES2016 and 6xiRES at the highest EV share.

When EV replace entirely conventional cars, $\mathrm{CO}_{2}$ emissions in the transport sector can be reduced by 13 and 12 percentage points respectively for Italy and Germany at the price of a rise in total electricity generation emissions (11 and 13 percentage points respectively) when RES are kept at 2016 level. As discussed previously (section 3.1), full transport electrification results in an overall decrease in emissions in Italy, while it leads to a slight increase in Germany, due to the carbon-intensive electricity generation sector of this country.

An increase in iRES capacity up to 6 times 2016 level allows a reduction in $\mathrm{CO}_{2}$ emission within the electricity generation, leading to a level that is comparable to the total 2016 emissions for the Italian case (30\% of the overall emissions) and even lower for Germany (22\%), that entails however a huge amount of RES surplus (as described previously).

Emissions due to transportation are still significantly affected by other means of transportation other than light-duty vehicles (heavy-duty vehicles, boat and air transport, etc) whose contribution, for both countries, represents $20-21 \%$ of the overall emissions in the best-case scenario. Such figure could be curbed by replacing petrol and diesel supply with electrofuels, these latter generated out of electricity (possibly from RES surplus), hydrogen and biomass [53]. At the present stage, however, electrofuels have not been included in the analysis. 


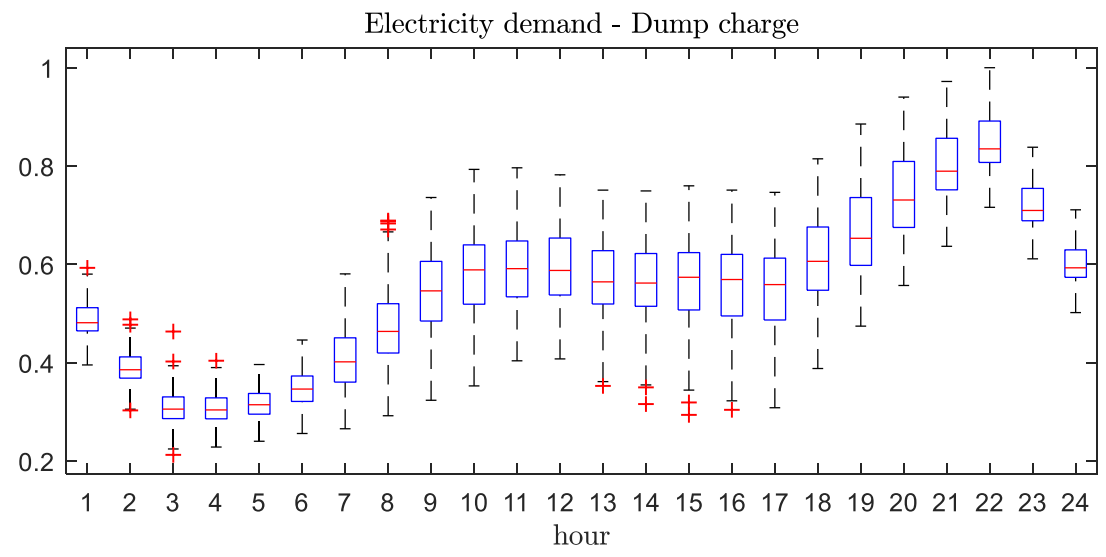

Electricity demand - Smart charge
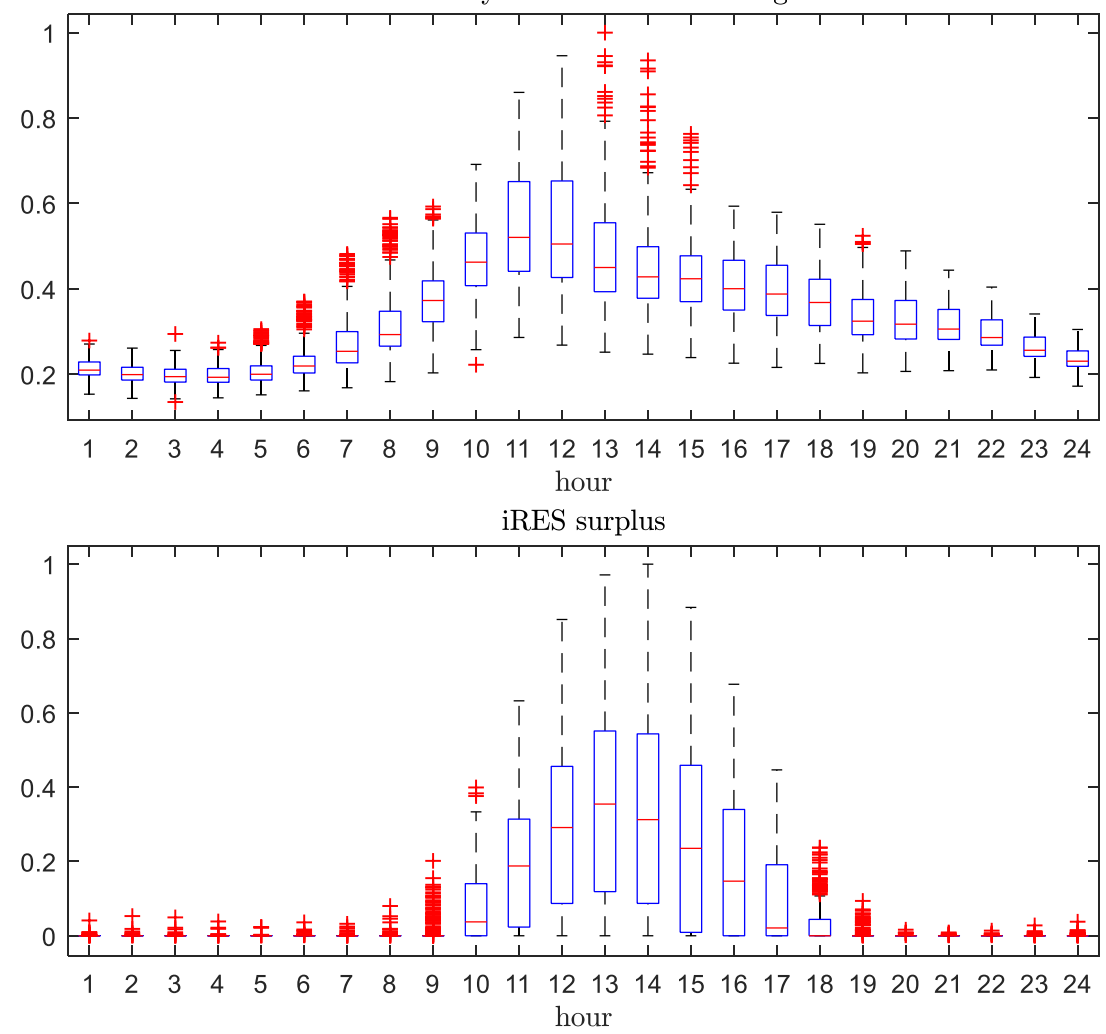

Figure 2. Daily distributions for the whole year of electricity demand under dump (top) and smart (center) EV charge and RES surplus (bottom). 6xiRES and 100\%EV scenario - Italy. 


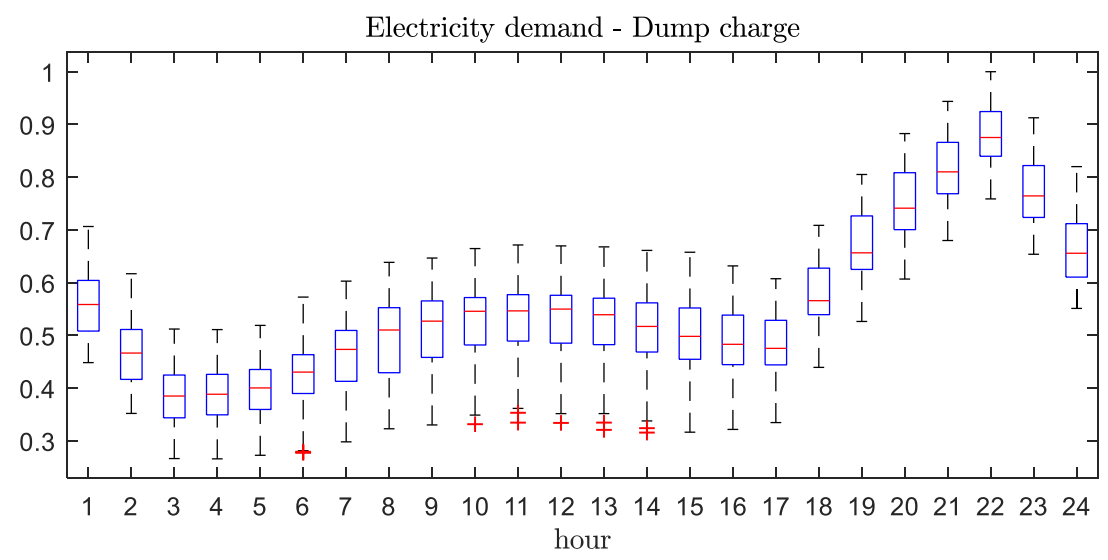

Electricity demand - Smart charge

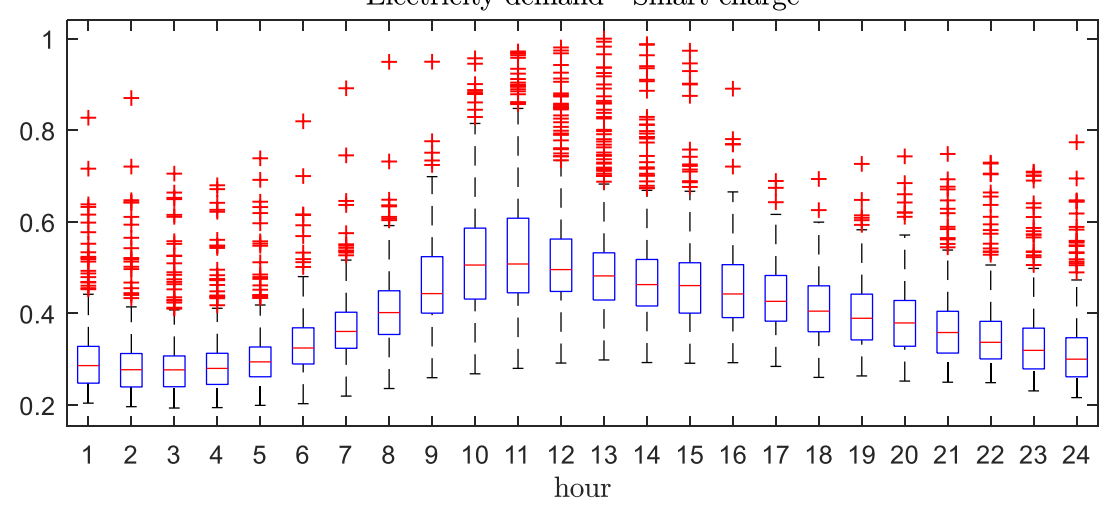

iRES surplus

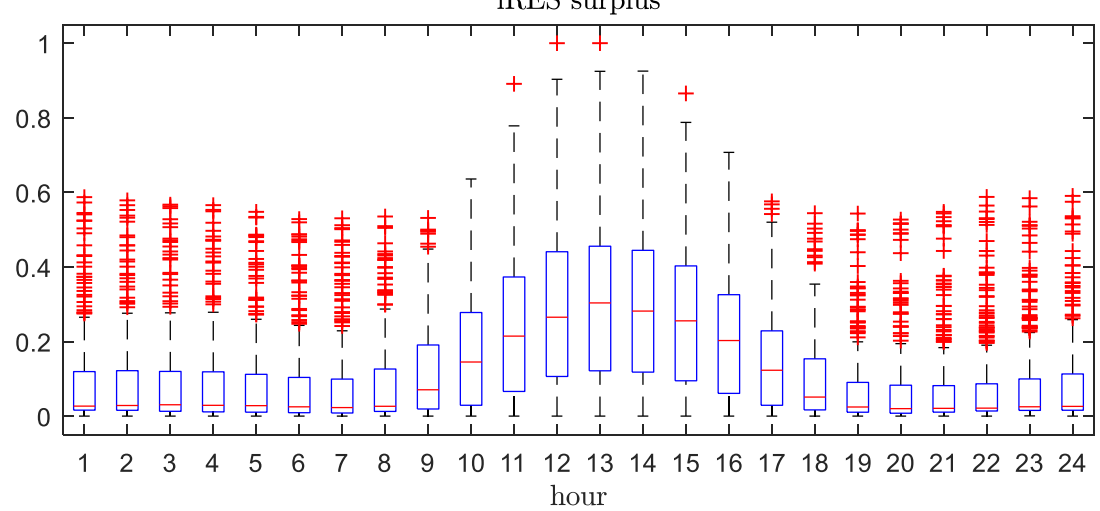

Figure 3. Daily distributions of electricity demand under dump (top) and smart (center) EV charge and RES surplus (bottom). 6xiRES and 100\%EV scenario - Germany. 


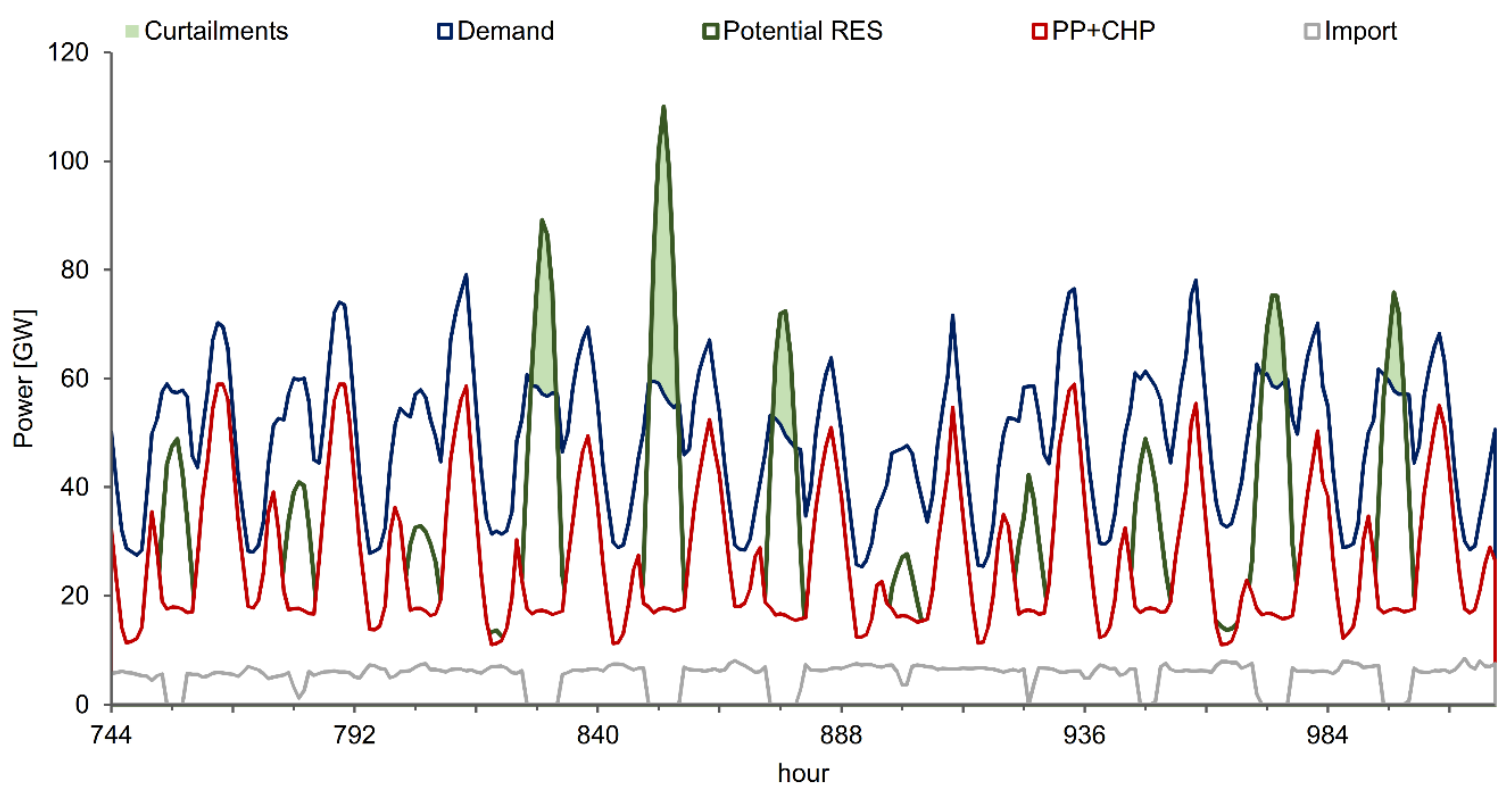

Figure 4. Power generation and demand at $100 \%$ EV and 6xiRES (Dump Charge) - Italy

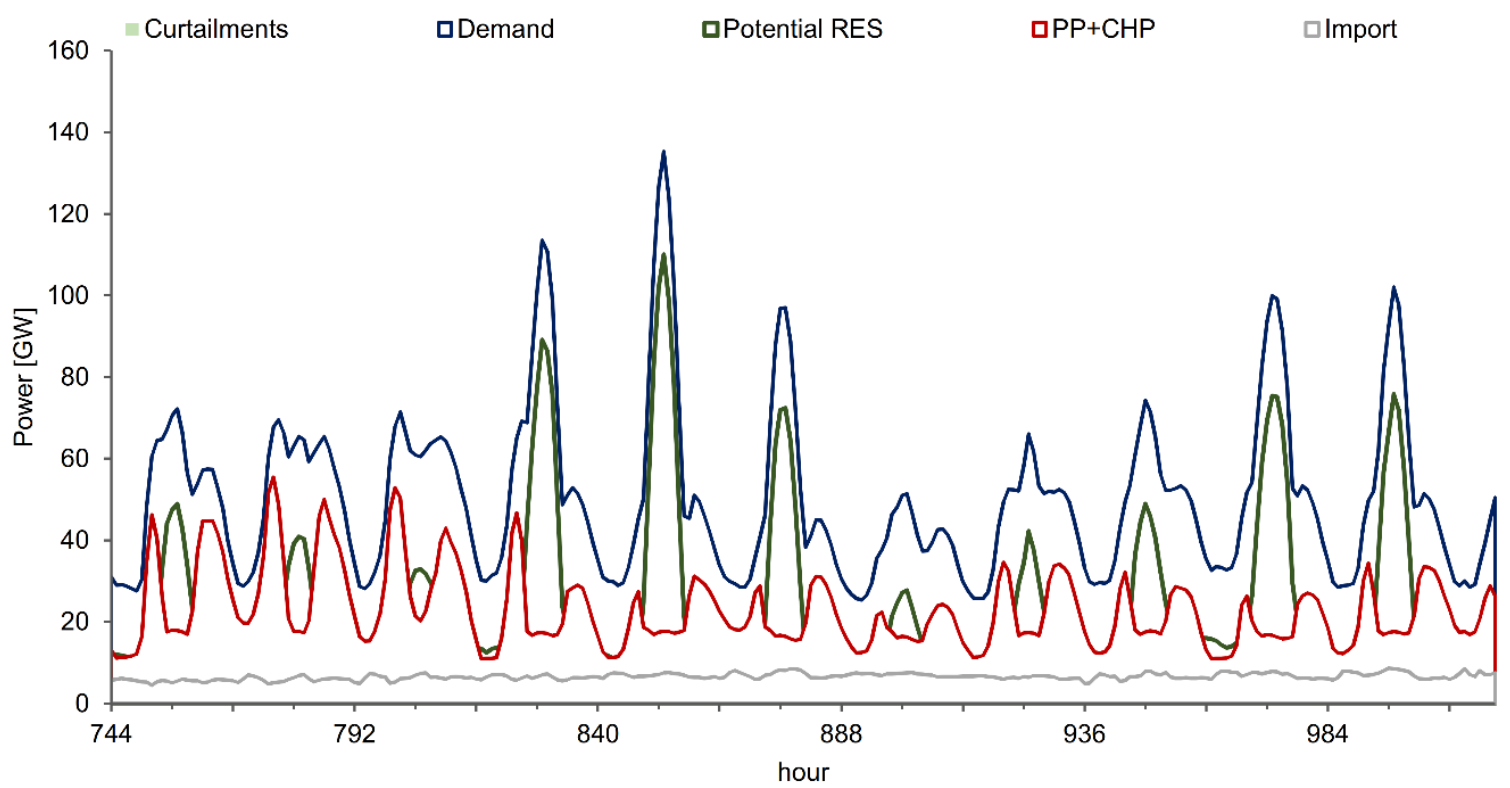

Figure 5. Power generation and demand at $100 \%$ EV and 6xiRES (Smart Charge) - Italy 


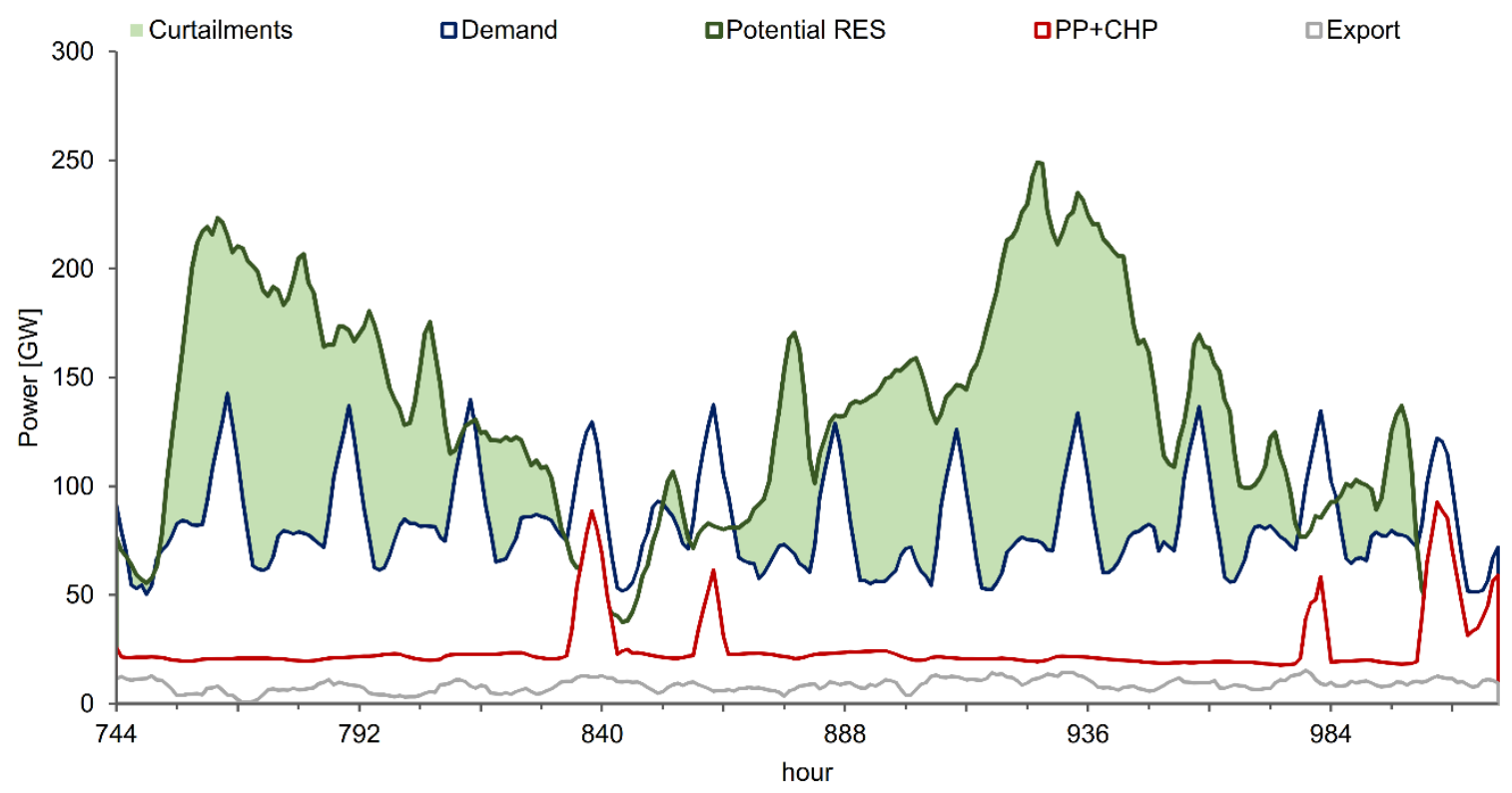

Figure 6. Power generation and demand at 100\% EV and 6xiRES (Dump Charge) - Germany

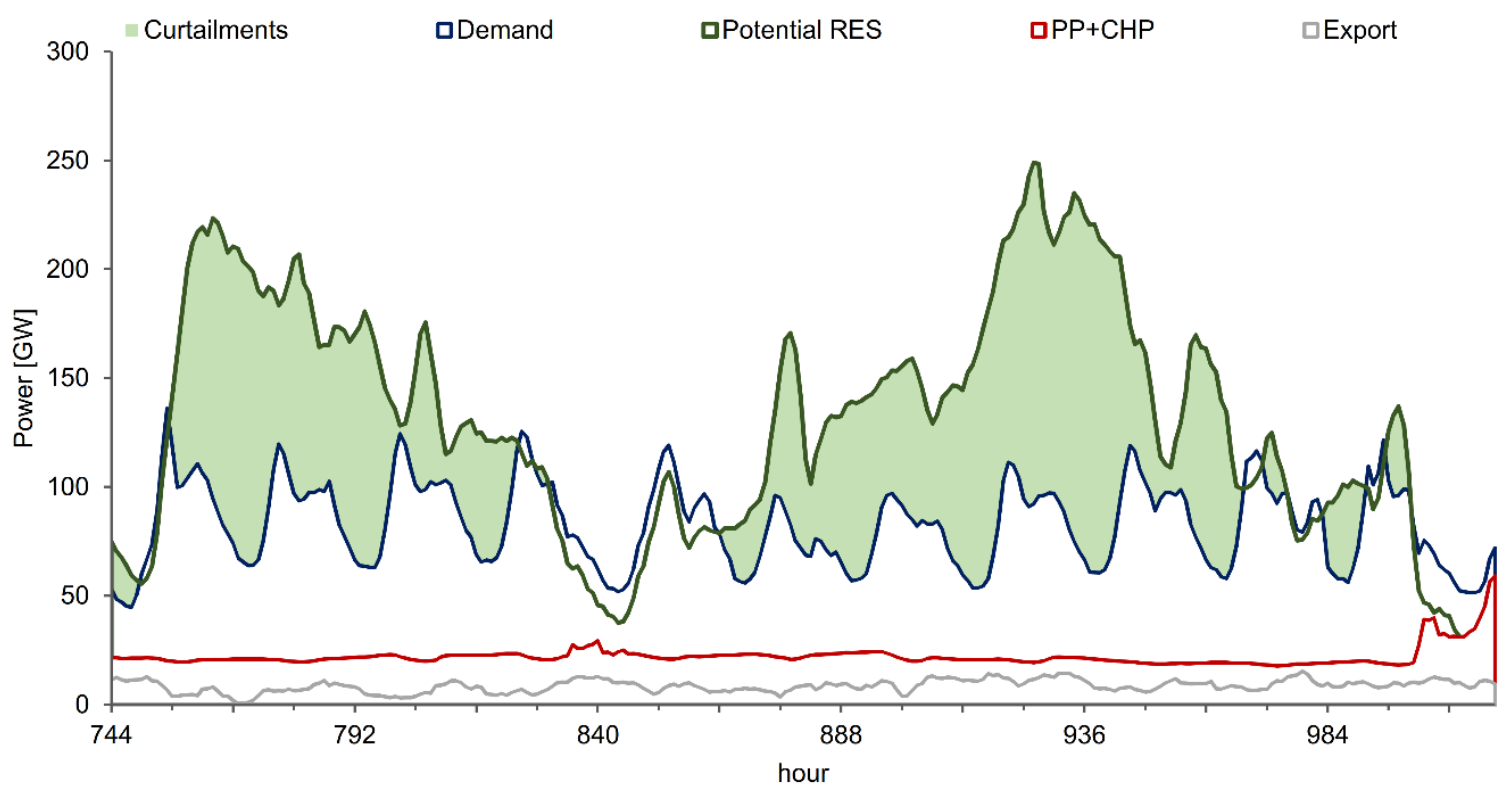

Figure 7. Power generation and demand at $100 \%$ EV and 6xiRES (Smart Charge) - Germany 

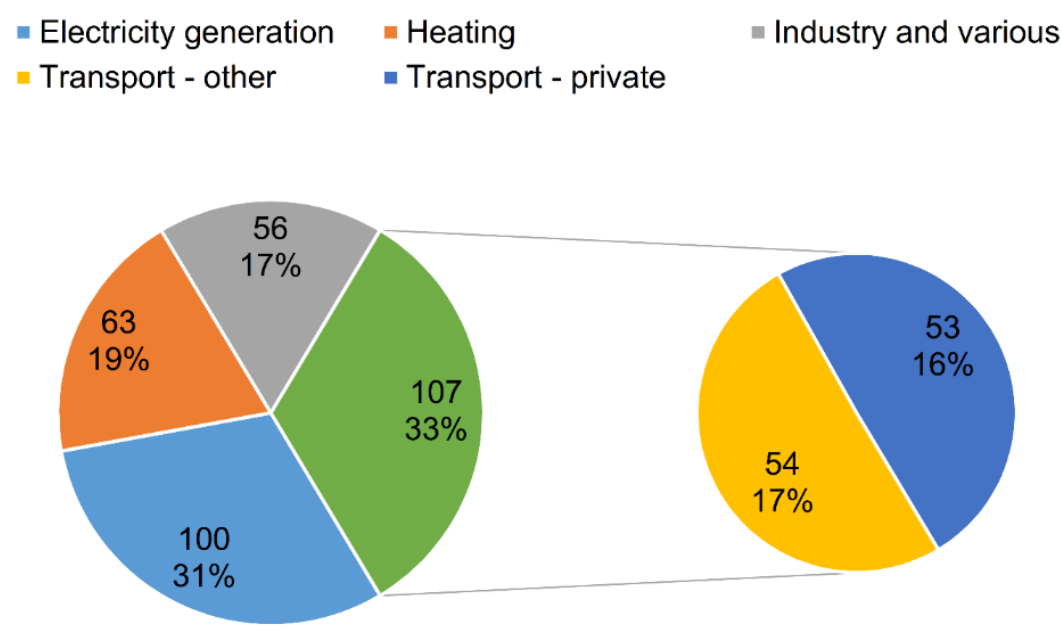

Figure 8. $\mathrm{CO}_{2}$ emissions (Mt) divided by sector (base-case) - Italy

$\begin{array}{ll}- \text { Electricity generation } & - \text { Heating } \\ =\text { Transport - other Industry and various }\end{array}$

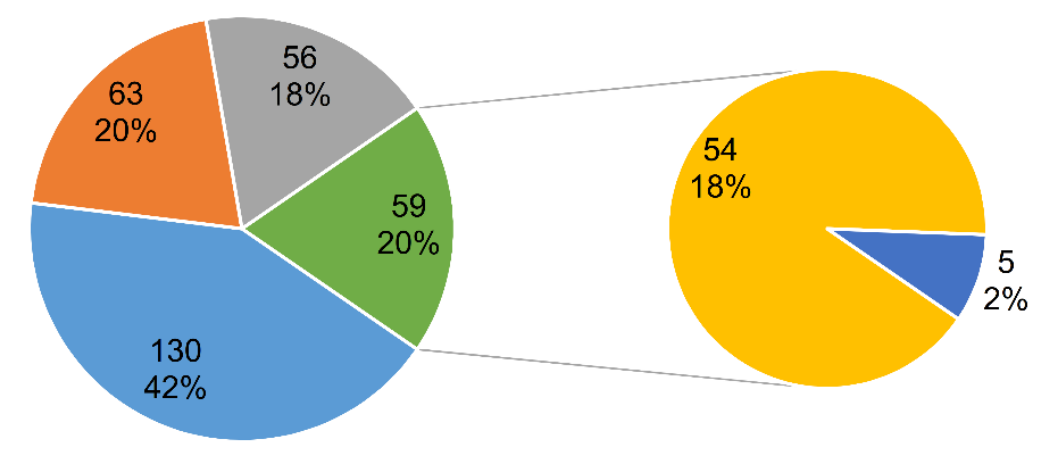

Figure 9. $\mathrm{CO}_{2}$ emissions (Mt) divided by sector (iRES2016 and 100\%EV) - Italy
- Electricity generation
- Heating
- Industry and various
- Transport - other
- Transport - private

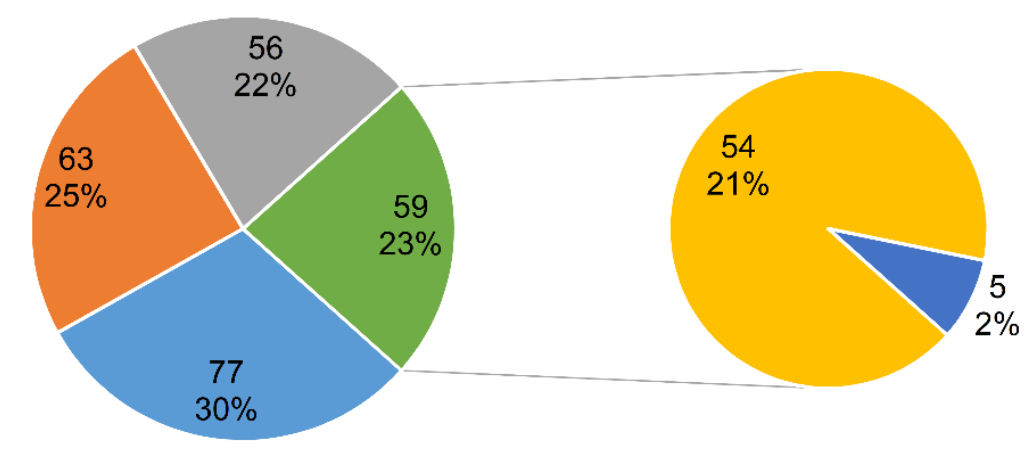

Figure 10. $\mathrm{CO}_{2}$ emissions (Mt) divided by sector (6xiRES and 100\%EV) - Italy 


$\begin{array}{ll}\text { - Electricity generation } & =\text { Heating } \\ =\text { Transport - other } & =\text { Transport - private Industry and various }\end{array}$

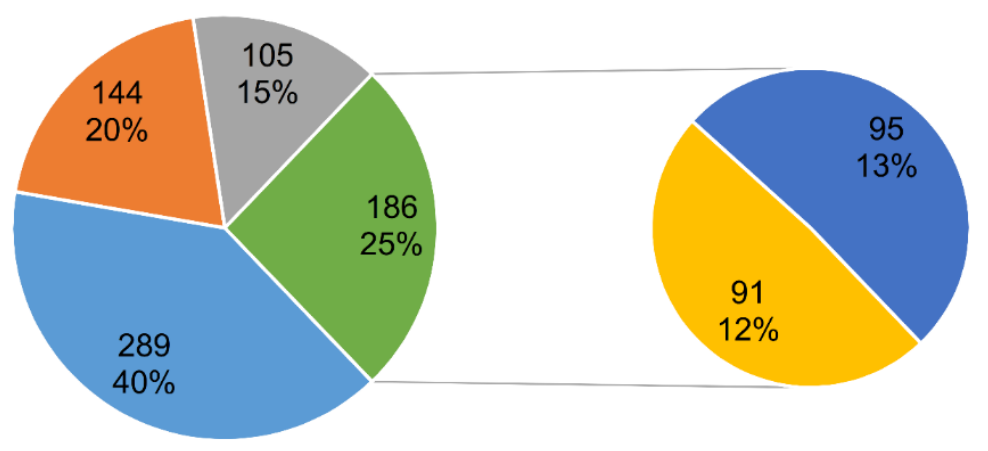

Figure 11. $\mathrm{CO}_{2}$ emissions (Mt) divided by sector (base-case) - Germany
- Electricity generation
= Transport - other
- Heating
- Industry and various
- Transport - private

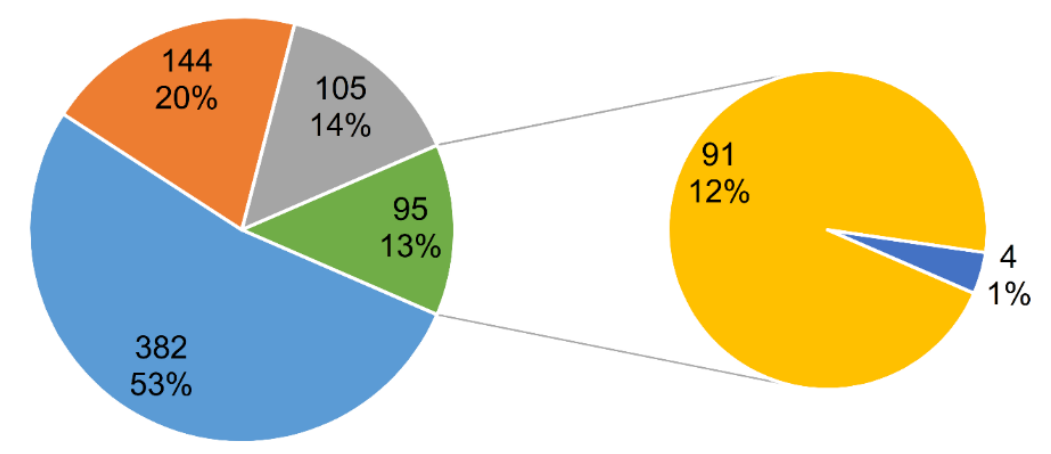

Figure 12. $\mathrm{CO}_{2}$ emissions (Mt) divided by sector (iRES2016 and 100\%EV) - Germany
- Electricity generation
- Heating
- Industry and various
- Transport - other
- Transport - private

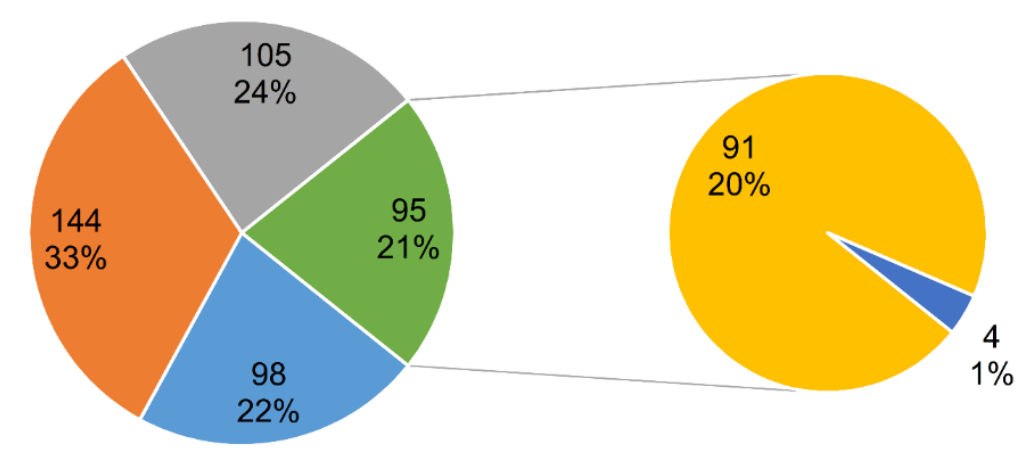

Figure 13. $\mathrm{CO}_{2}$ emissions (Mt) divided by sector (6xiRES and 100\%EV) - Germany 


\subsection{Coal and nuclear phase-out}

The effect of coal phase-out included in the energy strategies of both countries $[70,71]$ has been also assessed; results are shown in Table 20 when EV entirely replace the conventional vehicle fleet at the lowest and highest iRES installed capacity. The reduction of $\mathrm{CO}_{2}$ emissions is remarkable when coal is phased out from the German energy system; however, it occurs at the price of a considerable electricity import as the projected installed capacity is not adequate to cater for an increase in electricity demand. Import has been assumed to be fulfilled by PP by virtually increasing their available capacity, and corresponding emissions taking into account German PP specific emissions.

In this regard, while almost negligible for the Italian case, import can be as high as $44 \%$ of the total national production for the German case if RES capacity is kept at 2016 level. As a result, the energy mix of the country where electricity is imported from highly affects the overall sustainability of both coal and nuclear phase-out strategies.

Table 20. $\mathrm{CO}_{2}$ emissions and import - effect of coal and nuclear phase-out.

\begin{tabular}{lrrrr}
\hline & \multicolumn{2}{c}{ Italy } & \multicolumn{2}{c}{ Germany } \\
\hline & iRES2016 & 6xiRES & iRES2016 & 6xiRES \\
\hline $\mathrm{CO}_{2}[\%]$ & & & & \\
\hline No phase-out & $-5.2 \%$ & $-21.7 \%$ & $0.5 \%$ & $-39.2 \%$ \\
Coal phase-out & $-8.3 \%$ & $-23.3 \%$ & $-26.5 \%$ & $-45.1 \%$ \\
Coal and nuclear phase-out & - & - & $-22.3 \%$ & $-43.8 \%$ \\
\hline Additional import [\% of total production] & \multicolumn{5}{|c}{} \\
\hline No phase-out & $0.1 \%$ & $0.0 \%$ & $1.1 \%$ & $0.0 \%$ \\
Coal phase-out & $0.5 \%$ & $0.1 \%$ & $26.6 \%$ & $0.8 \%$ \\
Coal and nuclear phase-out & - & - & $43.9 \%$ & $2.0 \%$ \\
\hline
\end{tabular}

\subsection{Cost analysis}

A preliminary cost analysis was undertaken breaking down total annual costs in investments and variable costs according to EnergyPLAN subdivision.

Tables 21 and 22 report cost composition for iRES2016 and 6xiRES at 100\%EV, compared with the base case scenario assuming the different EV purchasing costs. Set to 100 total costs for the reference case, variable and investment costs were normalized accordingly:

$$
C_{\text {inorm }}=C_{i} / C_{\text {tot } 2016} \times 100
$$

Table 21. Total, investments and variable normalized costs at 2016 (base case) and iRES2016 and $6 \times$ iRES at $100 \% E V$ - Italy

\begin{tabular}{lrrr}
\hline & Base case 2016 & $\begin{array}{c}\text { 100\%EV } \\
\text { iRES2016 }\end{array}$ & $\begin{array}{r}\text { 100\%EV } \\
\text { 6xiRES }\end{array}$ \\
\hline Variable costs & 49.8 & 46.8 & 41.1 \\
of which $\mathrm{CO}_{2}$ emissions costs & 8.3 & 7.9 & 6.5 \\
Investments and O\&M (EV price @2016) & 50.2 & 85.9 & 89.0 \\
Investments and O\&M (EV price reduced) & 50.2 & 68.0 & 71.1 \\
Investments and O\&M (EV=Conventional) & 50.2 & 50.1 & 53.2 \\
\hline Total costs (EV price @2016) & 100.0 & 132.7 & 130.2 \\
Total costs (EV price reduced) & 100.0 & 114.8 & 112.3 \\
Total costs (EV=Conventional) & 100.0 & 96.9 & 94.3 \\
\hline
\end{tabular}


Table 22. Total, investments and variable normalized costs at 2016 (base case) and iRES2016 and $6 \times$ iRES at $100 \% E V$ - Germany

\begin{tabular}{lrrr}
\hline & Base case 2016 & \multicolumn{1}{c}{$\begin{array}{l}\text { 100\%EV } \\
\text { iRES2016 }\end{array}$} & \multicolumn{1}{c}{$\begin{array}{l}\text { 100\%EV } \\
\text { 6xiRES }\end{array}$} \\
\hline Variable costs & 40.7 & 37.3 & 28.1 \\
of which $\mathrm{CO}_{2}$ emissions costs & 10.0 & 10.1 & 6.1 \\
Investments and O\&M (EV price @2016) & 59.3 & 82.3 & 90.5 \\
Investments and O\&M (EV price reduced) & 66.7 & 70.8 & 79.1 \\
Investments and O\&M (EV=Conventional) & 66.7 & 59.3 & 67.6 \\
\hline Total costs (EV price @2016) & 100.0 & 119.6 & 118.6 \\
Total costs (EV price reduced) & 100.0 & 108.1 & 107.1 \\
Total costs (EV=Conventional) & 100.0 & 96.6 & 95.6 \\
\hline
\end{tabular}

For both countries, the increase investment costs due to both new RES installed capacity and EV is partly offset by a reduction in variable costs leading to an overall increase in total costs in the range 20$33 \%$ with respect to the base case scenario when EV price remains unchanged from 2016 level. As EV purchasing cost decreases so do investments costs ultimately leading to a reduction in total costs up to around $5 \%$ when the difference in EV and conventional cars' price is eventually evened out.

\subsection{Policy recommendations}

Electrification of transport is a priority in the European Community Research Program, due to several advantages related to EV, including higher "tank-to-wheel" efficiency with respect to traditional combustion engines, no tailpipe emissions of $\mathrm{CO}_{2}$ and pollutants at the point of use, and lower impacts in terms of noise and vibrations. Moreover, a key aspect is the possibility of increasing the share of RES in the transport sector through electricity generation, as deeply analyzed in this paper.

This last aspect is particularly of interest in Germany and Italy, where RES shares in electricity mixes are already reaching remarkable values. Both countries are currently supporting EV by providing tax incentives to EV owners, and Germany is also supporting the diffusion of EV with an environmental bonus for buyers. Both countries are also investing in the development of a charging infrastructure, which will be a crucial point for the diffusion and use of EV.

The results of this paper provide some valuable insights for the further development of EV supporting policies. The electricity generation mix is a crucial parameter for the success of reducing $\mathrm{CO}_{2}$ emissions through the diffusion of EV in any country. The comparison of Germany and Italy clearly highlights that a threshold exists in RES electricity share for an effective reduction of $\mathrm{CO}_{2}$ emissions. For this reason, an integrated energy policy is needed to couple the increase of EV diffusion to a parallel development of electricity generation from RES.

Again, as confirmed by the results of this work, without a careful support of RES electricity generation, the strong increase of EV penetration could potentially lead to an unwanted rebound effect, i.e. an increase of $\mathrm{CO}_{2}$ emissions in the transport sector. Attention must be paid also to the electricity profiles, to guarantee the optimal coupling between RES generation and EV charging logics and avoid the necessity of additional electricity import and/or conventional generation to offset the mismatch between RES potential production and increased electricity demand.

A policy support to smart charging solutions is essential to increase the benefits in terms of overall efficiency and $\mathrm{CO}_{2}$ emissions reduction. The main option to shift the electricity consumption during a specific time frame is to apply a different electricity price depending on the hour of the day, although for the final users these tariffs are generally fixed and unrelated with the wholesale prices, which in turn are more representative of the actual composition of the power mix. In Europe and Germany, the electricity price for final users is currently mainly made up by taxes and levies, rather than on the power generation price, thus complicating the definition of variable tariffs. Moreover, it is not clear if a small difference in the electricity price for the EV supply will suffice to shift the users' behavior towards smart charging strategies. It would also be necessary to dynamically adjust the power price depending on the live conditions of the network, but final users may require some guarantees on the maximum prices to accept this option. 
A more effective solution, as it is already happening in some contexts, may be the aggregation of a large number of $\mathrm{EV}$ into virtual power plants, which are the aggregation of a mix of distributed generation, storage and demand side management that are controlled and operated together to reach the required capacity to participate to the power market. While virtual power plants are currently mainly justified by economic advantages, as well as regulation limits on the access to wholesale markets, the remote operation of multiple EV by a single operator may result in an optimal management of the charging process. However, it has to be noted that for allowing such a smart charging, EV need to remain connected to charging stations for a longer duration, thus leading to the need of a higher vehicle/charging point ratio than for standard charging. Moreover, the users should be able to request a specific level of charge at the time they need it, depending on their specific habits, which may not always be in accordance with the optimal charging strategy.

Finally, it is useful to observe that, besides potentially reducing $\mathrm{CO}_{2}$ emissions, a significant adoption of EV in private transportation also contributes to improve air quality, which is an ever-increasing problem particularly in cities [55], and to increase energy security. In this respect, this study only focuses on investment and fuel costs variations; however, further analysis should be dedicated to include the abovementioned beneficial actions so as to assess the actual overall costs of EV penetration from a wider technical and socio-economic perspective.

\section{CONCLUSIONS}

This study aims to assess the impact of electric vehicles on energy systems characterised by a different supply mix for the electricity generation sector in the framework of a progressive increase of renewable energy sources capacity. Projections for possible future increase of renewable energy capacity have been implemented along with linearly growing shares of electric vehicles up to a total replacement of conventional vehicle fleet.

Results confirm that the electricity generation mix is a crucial parameter for the success of reducing $\mathrm{CO}_{2}$ emissions through the diffusion of electric vehicles in any country. In particular, electric vehicles penetration in the energy system curbs $\mathrm{CO}_{2}$ emissions for the German case provided that renewable capacity is increased up to a certain threshold (approximately twice the base case capacity) while in the Italian system electric private mobility proves to be sustainable even at the current renewable installed capacity.

With a sixfold increase in intermittent renewable sources capacity, and a complete replacement of conventional cars by electric vehicles, $\mathrm{CO}_{2}$ emissions can be reduced by $22 \%$ and $39 \%$ for Italy and Germany respectively at the price of a significant amount of curtailments (respectively $15 \%$ and $28 \%$ of the total national production).

Smart charge positively contributes to emissions reduction, more significantly for the Italian case due to the more uneven distribution of potential renewable power throughout the day with respect to Germany.

The higher installed capacity for renewables and electric vehicles penetration in the energy system result in higher investment costs, which are however mitigated by a variable costs reduction related to lower fuel consumption, thus leading to a total cost increase in the range $20-33 \%$ with respect to the base case scenario under the conservative assumption that electric vehicles price stays the same with respect to 2016 level.

\section{FUNDING}

This research did not receive any specific grant from funding agencies in the public, commercial, or notfor-profit sectors.

\section{DECLARATIONS OF INTEREST}

None. 


\section{APPENDIX}

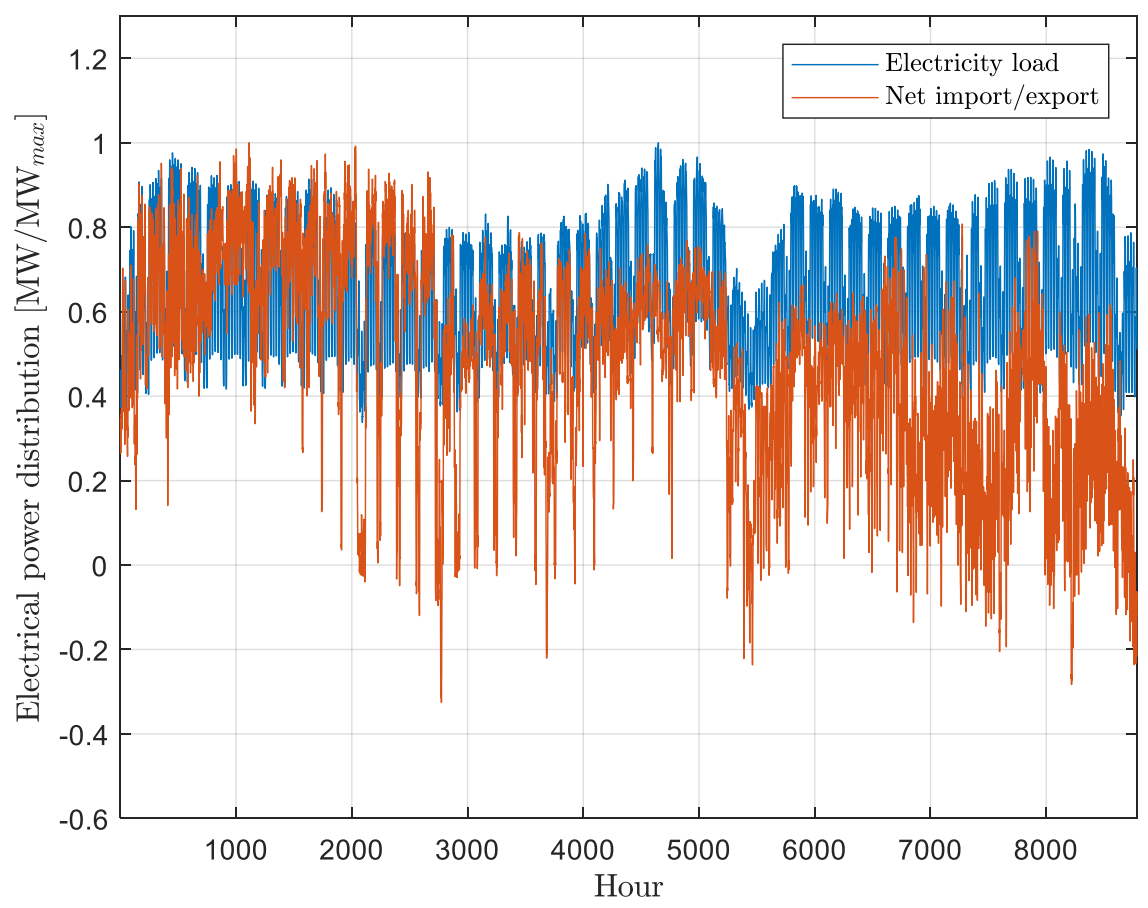

Figure A.1. Electricity demand and net import/export hourly distribution: Italy at 2016 (Sources:[56,57])

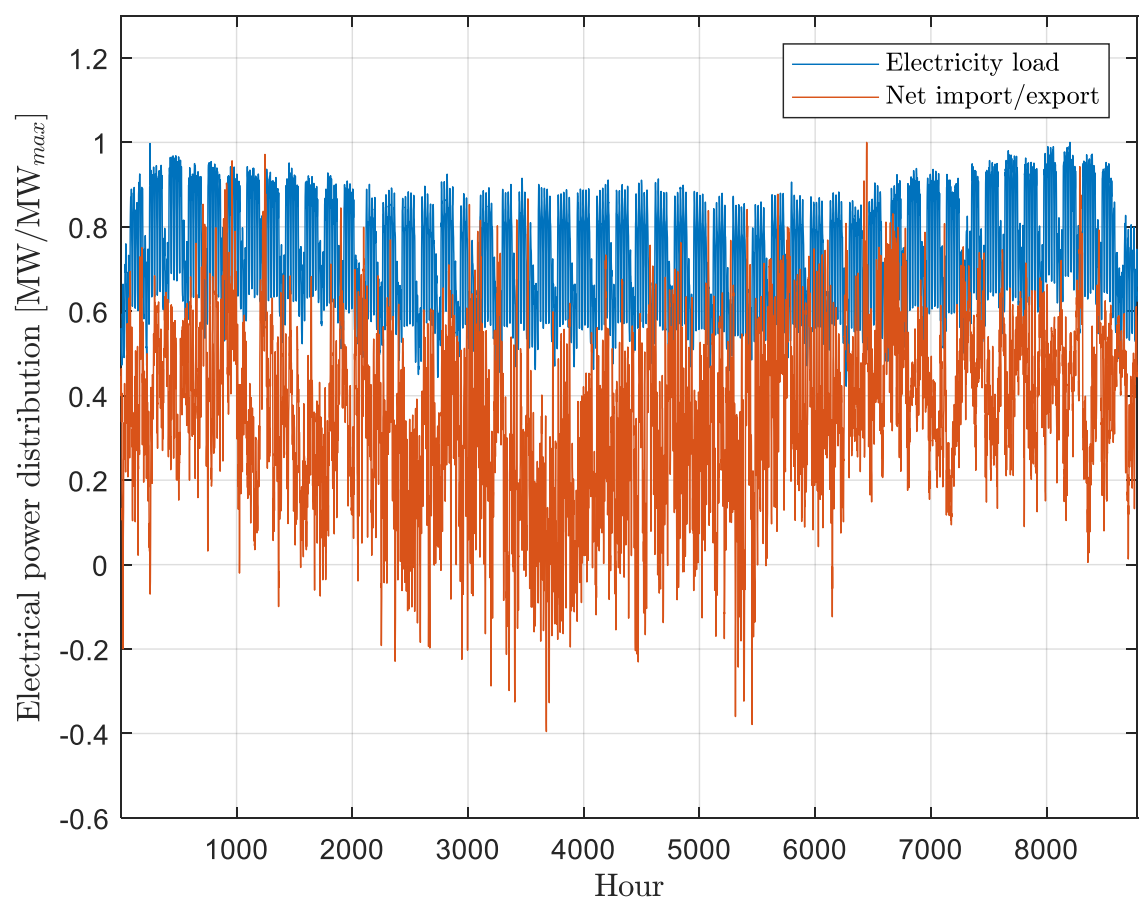

Figure A.2. Electricity demand and net import/export hourly distributions: Germany at 2016 (Source:[58,59]) 


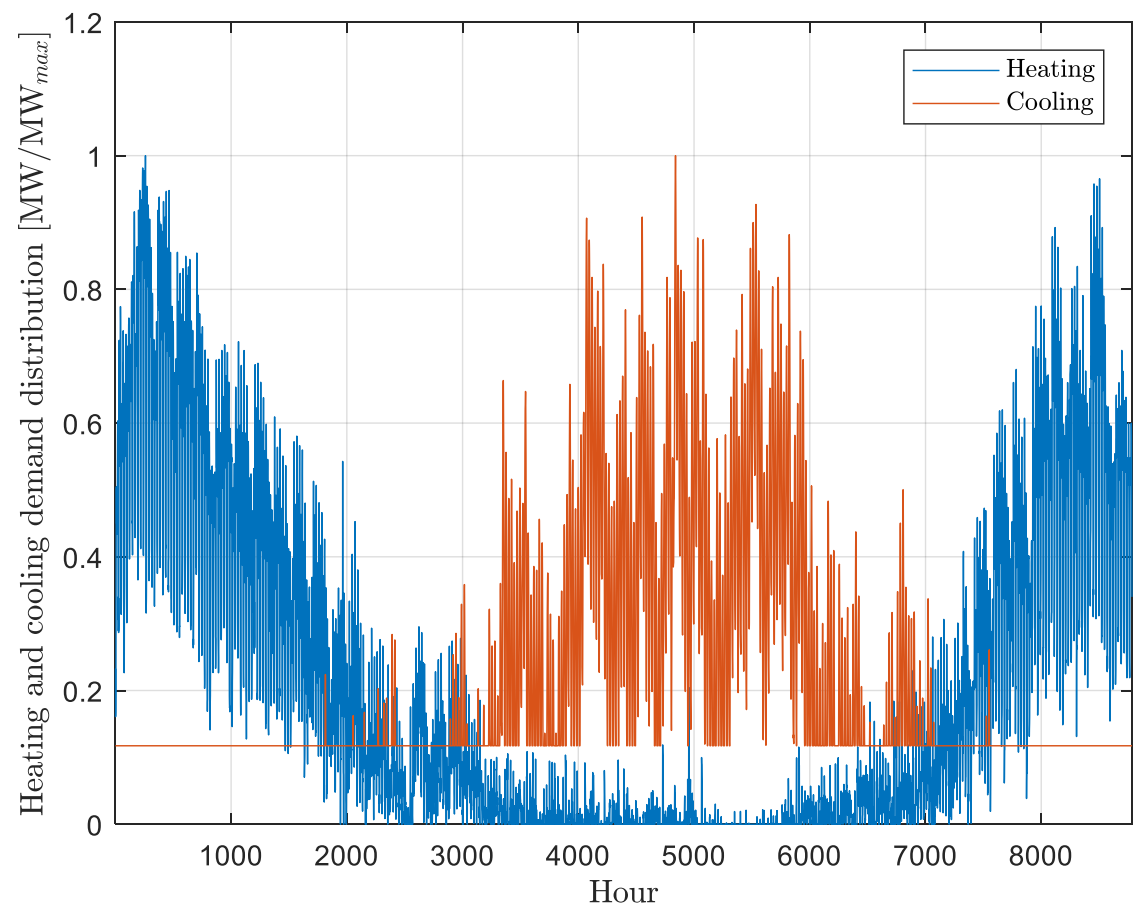

Figure A.3. Heating and cooling demand hourly distributions: Italy at 2016 (Sources:[27,34])

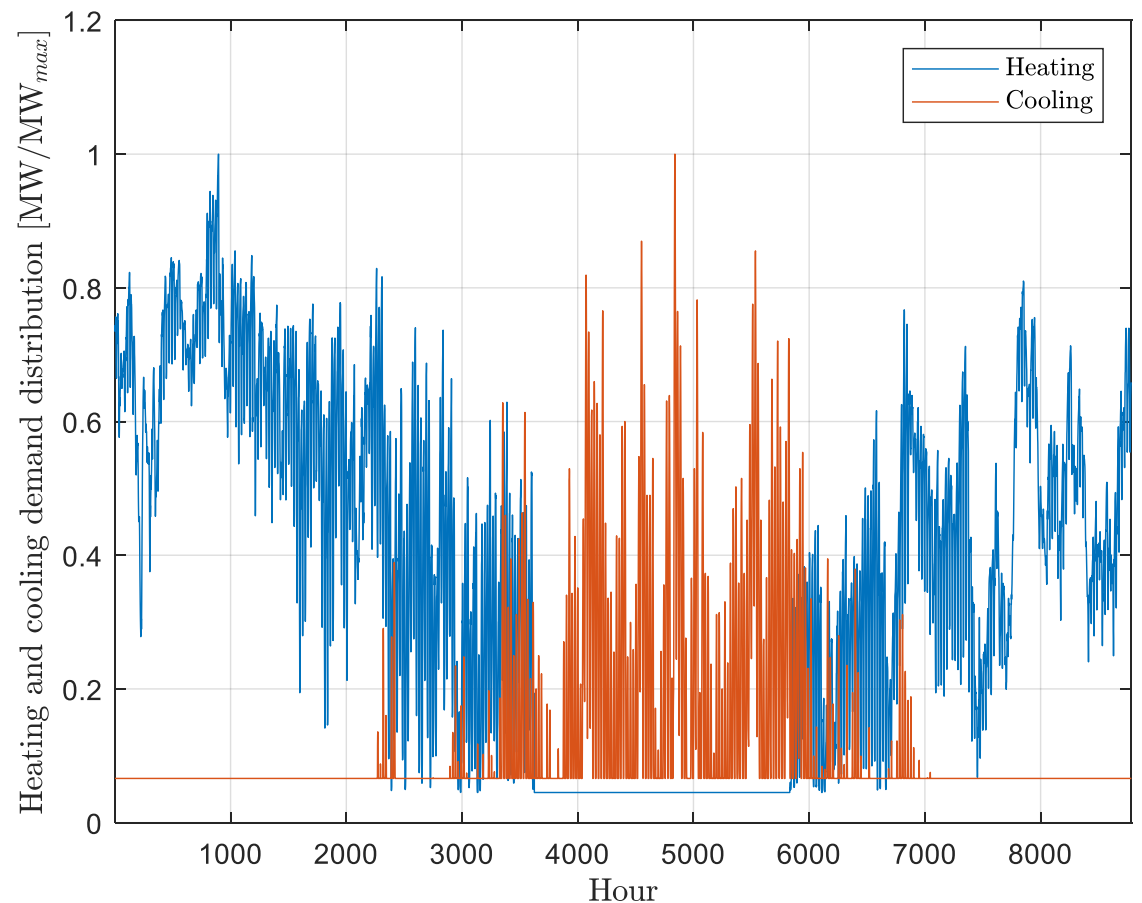

Figure A.4. Heating and cooling demand hourly distributions: Germany at 2016 (Source:[27]) 


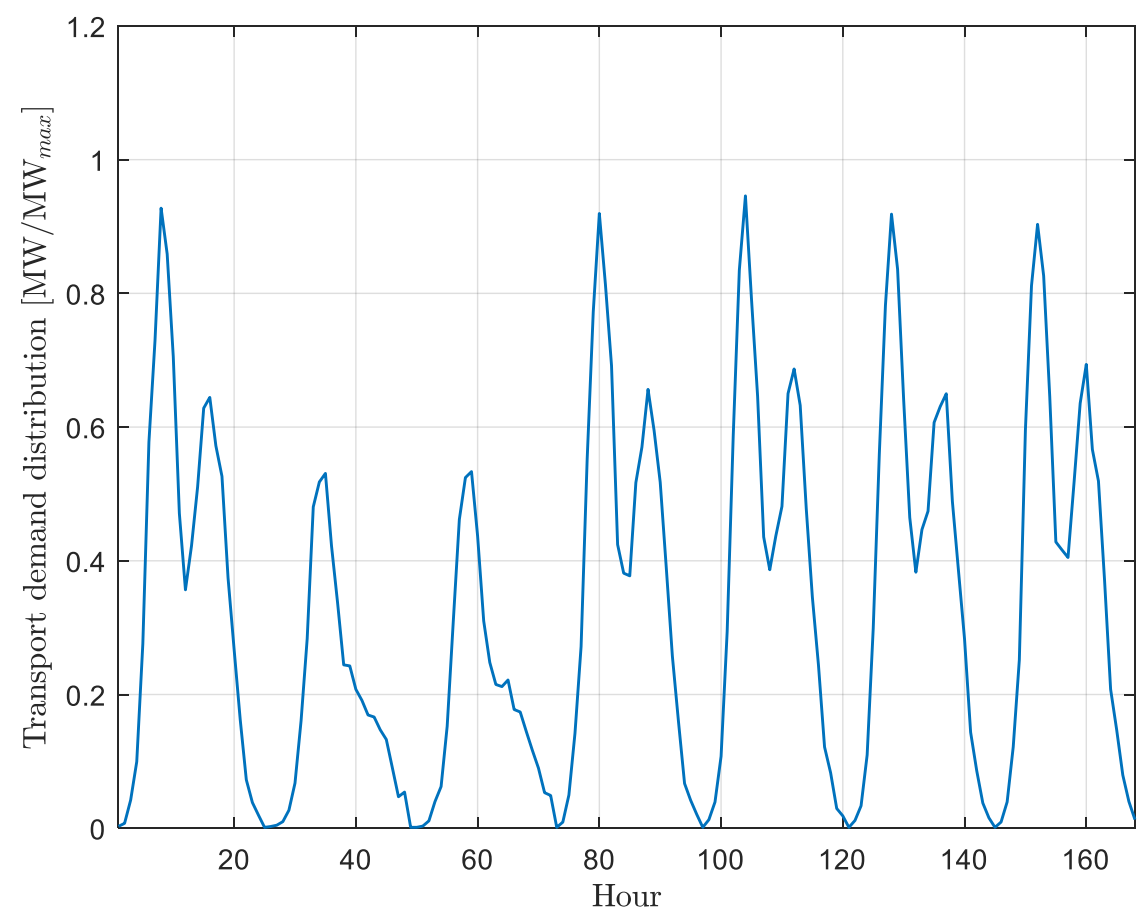

Figure A.5. Hourly distribution of transportation demand (discharging of EV battery) for 1 week, valid for both Germany and Italy [27].

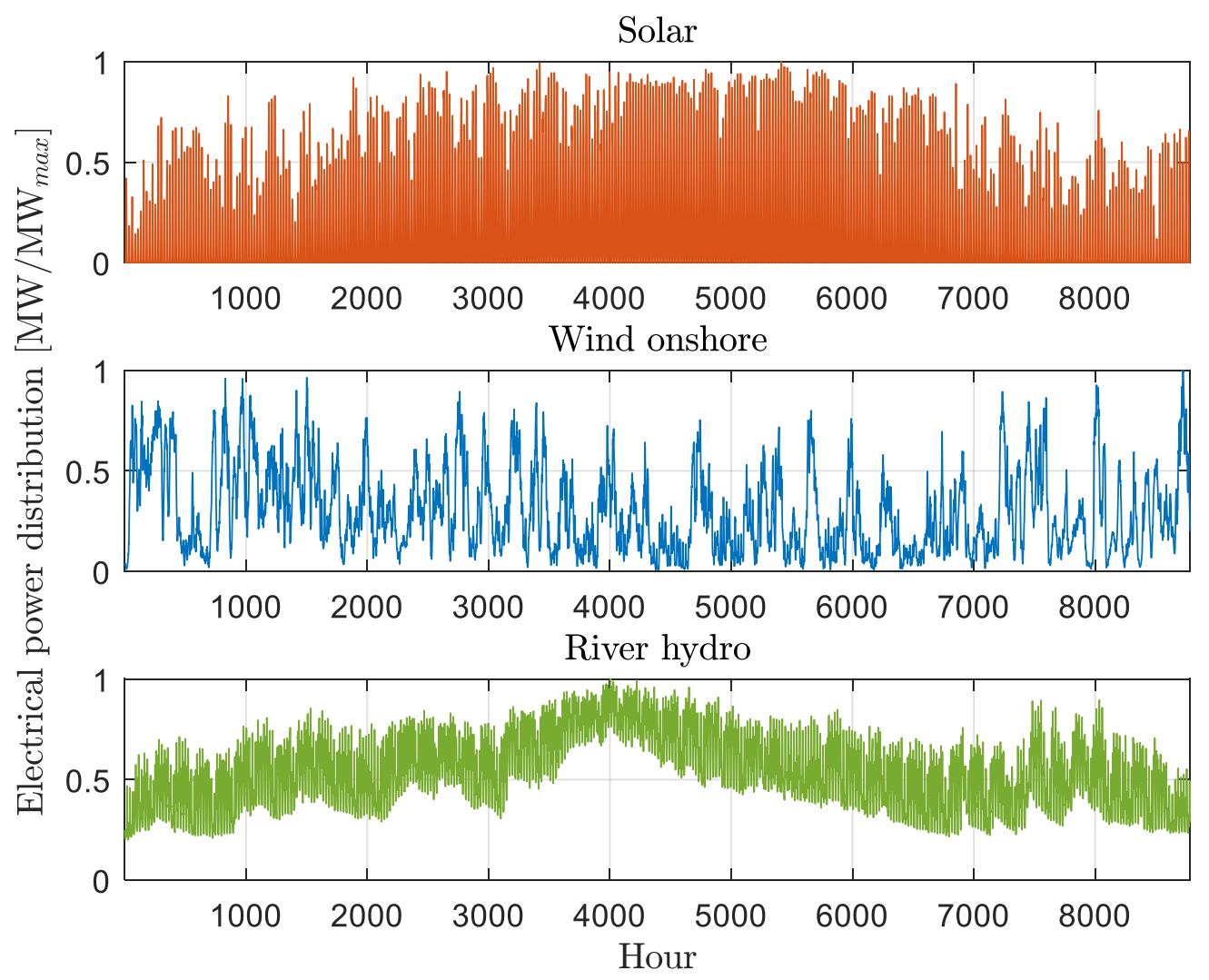

Figure A.6. Distribution of renewable electricity generation: Italy at 2016 (Source:[39]) 


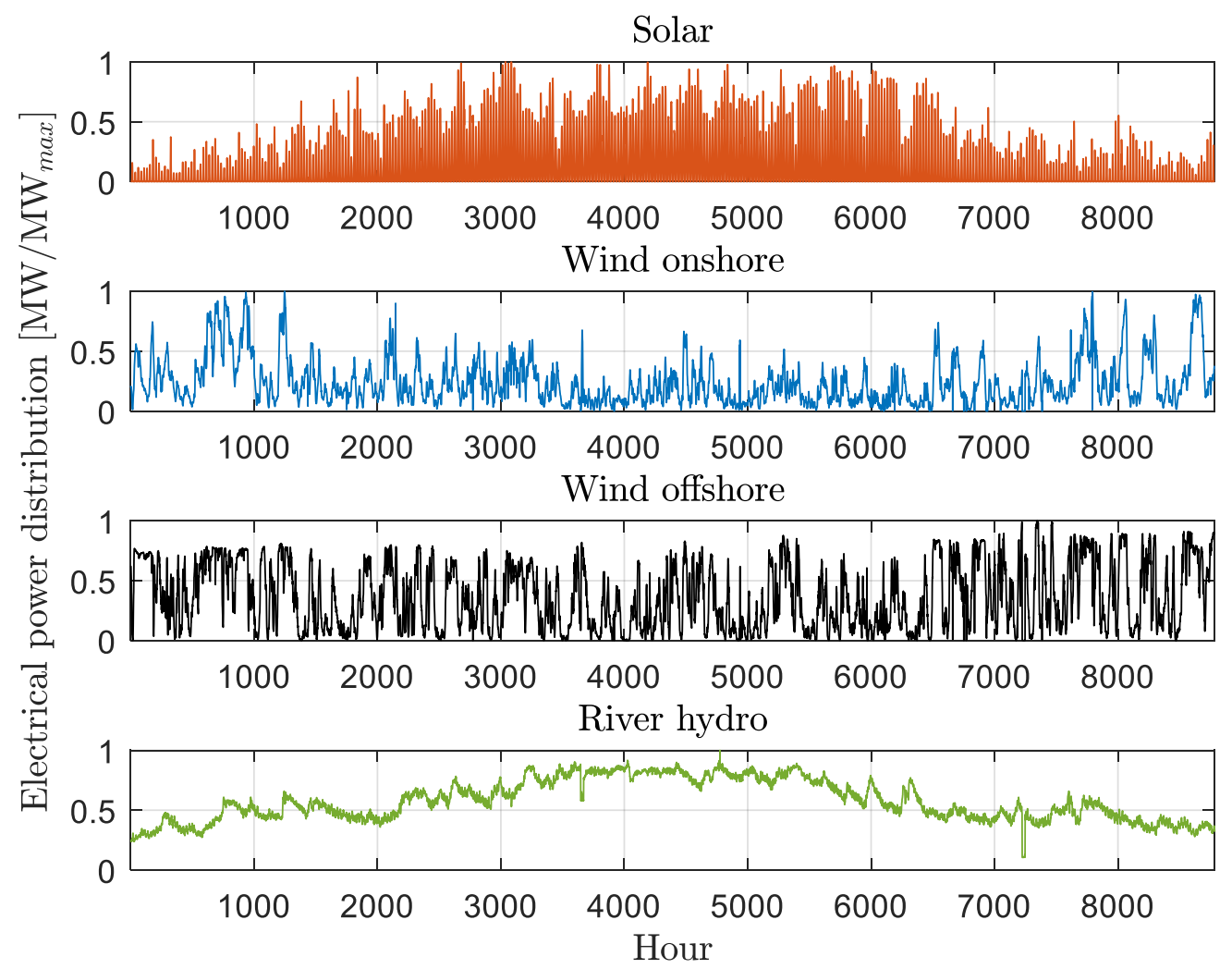

Figure A.7. Distribution of renewable electricity generation: Germany at 2016 (Source:[40])

\section{REFERENCES}

[1] United Nations. The Paris Agreement | UNFCCC 2015. https://unfccc.int/process-andmeetings/the-paris-agreement/the-paris-agreement (accessed July 17, 2019).

[2] Energy. UN Environ 2019. http://www.unenvironment.org/explore-topics/energy (accessed July 17, 2019).

[3] Transport. UN Environ 2019. http://www.unenvironment.org/explore-topics/transport (accessed July 17,2019$)$.

[4] International Energy Agency. Sankey Diagram: Balance 2016. https://www.iea.org/sankey/\#?c=World\&s=Balance (accessed July 17, 2019).

[5] International Energy Agency. Sankey Diagram: Final consumption 2016. https://www.iea.org/sankey/\#?c=World\&s=Final\%20consumption (accessed July 17, 2019).

[6] Bellocchi S, Gambini M, Manno M, Stilo T, Vellini M. Positive interactions between electric vehicles and renewable energy sources in CO2-reduced energy scenarios: The Italian case. Energy 2018;161:172-82. doi:10.1016/J.ENERGY.2018.07.068.

[7] Buonomano A, Calise F, Cappiello FL, Palombo A, Vicidomini M. Dynamic analysis of the integration of electric vehicles in efficient buildings fed by renewables. Appl Energy 2019;245:3150. doi:10.1016/j.apenergy.2019.03.206.

[8] Prina MG, Lionetti M, Manzolini G, Sparber W, Moser D. Transition pathways optimization methodology through EnergyPLAN software for long-term energy planning. Appl Energy 2019;235:356-68. doi:10.1016/j.apenergy.2018.10.099.

[9] Zhang T, Pota H, Chu C-C, Gadh R. Real-time renewable energy incentive system for electric vehicles using prioritization and cryptocurrency. Appl Energy 2018;226:582-94. doi:10.1016/j.apenergy.2018.06.025.

[10] Shaukat N, Khan B, Ali SM, Mehmood CA, Khan J, Farid U, et al. A survey on electric vehicle transportation within smart grid system. Renew Sustain Energy Rev 2018;81:1329-49. doi:10.1016/j.rser.2017.05.092.

[11] Hanemann P, Behnert M, Bruckner T. Effects of electric vehicle charging strategies on the German power system. Appl Energy 2017;203:608-22. doi:10.1016/j.apenergy.2017.06.039. 
[12] Seddig K, Jochem P, Fichtner W. Two-stage stochastic optimization for cost-minimal charging of electric vehicles at public charging stations with photovoltaics. Appl Energy 2019;242:769-81. doi:10.1016/j.apenergy.2019.03.036.

[13] Forrest KE, Tarroja B, Zhang L, Shaffer B, Samuelsen S. Charging a renewable future: The impact of electric vehicle charging intelligence on energy storage requirements to meet renewable portfolio standards. J Power Sources 2016;336:63-74. doi:10.1016/j.jpowsour.2016.10.048.

[14] Schill W-P, Gerbaulet C. Power system impacts of electric vehicles in Germany: Charging with coal or renewables? Appl Energy 2015;156:185-96. doi:10.1016/j.apenergy.2015.07.012.

[15] Nunes P, Farias T, Brito MC. Enabling solar electricity with electric vehicles smart charging. Energy 2015;87:10-20. doi:10.1016/j.energy.2015.04.044.

[16] Novosel T, Perković L, Ban M, Keko H, Pukšec T, Krajačić G, et al. Agent based modelling and energy planning - Utilization of MATSim for transport energy demand modelling. Energy 2015;92:466-75. doi:10.1016/j.energy.2015.05.091.

[17] Pfeifer A, Krajačić G, Ljubas D, Duić N. Increasing the integration of solar photovoltaics in energy mix on the road to low emissions energy system - Economic and environmental implications. Renew Energy 2019;143:1310-7. doi:10.1016/j.renene.2019.05.080.

[18] Lund $\mathrm{H}$, Kempton $\mathrm{W}$. Integration of renewable energy into the transport and electricity sectors through V2G. Energy Policy 2008;36:3578-87. doi:10.1016/j.enpol.2008.06.007.

[19] Rupp M, Handschuh N, Rieke C, Kuperjans I. Contribution of country-specific electricity mix and charging time to environmental impact of battery electric vehicles: A case study of electric buses in Germany. Appl Energy 2019;237:618-34. doi:10.1016/j.apenergy.2019.01.059.

[20] EnergyPLAN - Advanced energy systems analysis computer model. EnergyPLAN 2019. https://www.energyplan.eu/ (accessed July 19, 2019).

[21] Manno M, Bellocchi S. Dataset for: "On the role of electric vehicles towards low-carbon energy systems: Italy and Germany in comparison" 2019. doi:10.5281/zenodo.3353737.

[22] International Energy Agency. Statistics | Italy: Electricity and heat for 2016. https://www.iea.org/statistics/?country=ITALY\&year=2016\&category=Energy\%20supply\&indicato $r=$ TPESbySource\&mode=table\&dataTable=ELECTRICITYANDHEAT (accessed July 19, 2019).

[23] International Energy Agency. Statistics | Germany: Electricity and heat for 2016. https://www.iea.org/statistics/?country=GERMANY\&year=2016\&category=Energy\%20supply\&in dicator=TPESbySource\&mode=table\&dataTable=ELECTRICITYANDHEAT (accessed July 19, 2019).

[24] International Energy Agency. Statistics | Italy: Balances for 2016. https://www.iea.org/statistics/?country=ITALY\&year=2016\&category=Energy\%20supply\&indicato $r=$ TPESbySource\&mode=table\&dataTable=BALANCES (accessed July 19, 2019).

[25] International Energy Agency. Future of cooling 2018. https://www.iea.org/futureofcooling/ (accessed July 19, 2019).

[26] Gestore Servizi Energetici. Valutazione del potenziale nazionale e regionale di applicazione della cogenerazione ad alto rendimento e del teletricaldamento efficiente 2016.

[27] Energy Models - Heat Roadmap Europe 2018. https://heatroadmap.eu/energy-models/ (accessed July 19, 2019).

[28] Zebra2020. Datamapper - Scenarios of the market transition to nZEBs 2016. https://eeg.tuwien.ac.at/zebra/ (accessed July 19, 2019).

[29] Gestore Servizi Energetici. Energia da fonti rinnovabili in Italia 2016.

[30] Federal Ministry for Economic Affairs and Energy. Development of Renewable Energy Sources in Germany 2018.

[31] Dr.-Ing. Marek Miara*, Dipl.-Wi.-Ing. (FH) Danny Günther, Dipl.-Ing. (FH) Robert Langner, Dipl.Ing. Sebastian Helmling, Dipl.-Ing. (FH) Jeannette Wapler. 10 years of heat pumps monitoring in Germany. Outcomes of several monitoring campaigns. From low-energy houses to un-retrofitted single-family dwellings., Rotterdam: 2017.

[32] International Energy Agency. Statistics | Germany: Balances for 2016. https://www.iea.org/statistics/?country=GERMANY\&year=2016\&category=Energy\%20supply\&in dicator=TPESbySource\&mode=table\&dataTable=BALANCES (accessed July 19, 2019).

[33] Noussan M, Nastasi B. Data Analysis of Heating Systems for Buildings-A Tool for Energy Planning, Policies and Systems Simulation. Energies 2018;11:233. doi:10.3390/en11010233.

[34] Società Nazionale Metanodotti. Operating data - physical flows on the national network 2016. http://www.snam.it/en/transportation/operational-data-business/0-

Phisical_Flows_on_the_national_network/(accessed July 19, 2019).

[35] Istituto Superiore per la Protezione e la Ricerca Ambientale. Trasporti 2017. 
[36] AG Energiebilanzen e.V. Energy Balance 2000 to 2017 2016. https://ag-energiebilanzen.de/7-1Energy-Balance-2000-to-2015.html (accessed July 19, 2019).

[37] Terna Rete Italia. Dati statistici sull'energia elettrica in Italia 2016. http://www.terna.it/itit/sistemaelettrico/statisticheeprevisioni/datistatistici.aspx (accessed July 19, 2019).

[38] Bundesnetzagentur - List of Power 2016. https://www.bundesnetzagentur.de/EN/Areas/Energy/Companies/SecurityOfSupply/GeneratingC apacity/PowerPlantList/PubliPowerPlantList_node.html (accessed July 19, 2019).

[39] Terna Rete Italia. Ex post data on the actual generation 2016. http://www.terna.it/SistemaElettrico/TransparencyReport/Generation/Expostdataontheactualgene ration.aspx (accessed July 19, 2019).

[40] entso e. Actual Generation per Production Type - Germany 2016. https://transparency.entsoe.eu/ (accessed July 19, 2019).

[41] Associazione Nazionale Energia del Vento. II potenziale eolico nazionale. ANEV 2018. https://www.anev.org/services/italia-2030/ (accessed July 23, 2019).

[42] Dr. K. Rohrig, C. Richts, Dr. S. Bofinger, M. Jansen, M. Siefert, S. Pfaffel, M. Durstewitz. Energiewirtschaftliche Bedeutung der Offshore-Windenergie. Fraunhofer-Inst Für Energiewirtschaft $\quad$ Energiesystemtechnik 2013. https://www.iee.fraunhofer.de/de/projekte/suche/2013/energiewirtschaftliche_bedeutung_der_off shore_windenergie.html (accessed July 23, 2019).

[43] Unione Petrolifera. Previsioni di domanda energetica e petrolifera 2018-2030 2018. https://www.unionepetrolifera.it/pubblicazioni/ (accessed July 23, 2019).

[44] Federal Ministry for the Environment, Nature Conservation Building and Nuclear Safety. Climate Action Plan 2050. bmu.de 2016. https://www.bmu.de/PU395-1 (accessed July 23, 2019).

[45] Unione Nazionale Rappresentanti Autoveicoli Esteri. L'AUTO 2017.

[46] Löhr E, Kirsch F, Jones L. Exploration of EU road vehicle fuel consumption and disaggregation 2016:152.

[47] Europe's Evolving Passenger Vehicle Fleet: Fuel Use and GHG Emissions Scenarios through 2035. Main n.d. http://energy.mit.edu/publication/europes-evolving-passenger-vehicle-fleet-fueluse-and-ghg-emissions-scenarios-through-2035/ (accessed July 23, 2019).

[48] Kraftfahrt-Bundesamt. Motor vehicle 2018. https://www.kba.de/EN/Statistik_en/statistik_node_en.html (accessed July 23, 2019).

[49] EV Database. EV Database 2019. https://ev-database.org/ (accessed July 23, 2019).

[50] Bloomberg New Energy Finance. Electric Vehicle Outlook. BloombergNEF 2019. https://about.bnef.com/electric-vehicle-outlook/ (accessed July 23, 2019).

[51] Union of Concerned Scientists. Accelerating US Leadership in Electric Vehicles 2018.

[52] Nykvist B, Nilsson M. Rapidly falling costs of battery packs for electric vehicles. Nat Clim Change 2015;5:329-32. doi:10.1038/nclimate2564.

[53] Bellocchi S, De Falco M, Gambini M, Manno M, Stilo T, Vellini M. Opportunities for power-to-Gas and Power-to-liquid in CO2-reduced energy scenarios: The Italian case. Energy 2019;175:84761. doi:10.1016/j.energy.2019.03.116.

[54] Bellocchi S, Manno M, Noussan M, Vellini M. Impact of Grid-Scale Electricity Storage and Electric Vehicles on Renewable Energy Penetration: A Case Study for Italy. Energies 2019;12:1303. doi:10.3390/en12071303.

[55] European Commission. Cleaner air for all 2019. https://ec.europa.eu/environment/air/cleaner_air/ (accessed July 29, 2019).

[56] Terna Rete Italia. Actual Load 2016. http://www.terna.it/SistemaElettrico/TransparencyReport/Load/ActualLoad.aspx (accessed July 23, 2019)

[57] entso e. Cross-border physical flow - Italy 2016. https://transparency.entsoe.eu/ (accessed July 23, 2019).

[58] entso e. Total Load - Day Ahead / Actual - Germany 2016. https://transparency.entsoe.eu/ (accessed July 23, 2019).

[59] entso e. Cross-border physical flow - Germany 2016. https://transparency.entsoe.eu/ (accessed July 23, 2019). 